\title{
SURE E GARAPA: CARACTERIZAÇÃO MOLECULAR E DISTRIBUIÇÃO DE DOIS RETROTRANSPOSONS COM LTR DE CANA-DE-AÇÚCAR
}

\section{DOUGLAS SILVA DOMINGUES}

Tese (Doutorado) apresentada ao Programa de Pós-Graduação Interunidades em Biotecnologia USP/Instituto Butantan/IPT, para obtenção do Título de Doutor em Biotecnologia.

Área de Concentração: Biotecnologia

Orientador: Profa. Dra. Marie-Anne Van Sluys 


\section{Resumo}

Domingues DS. SURE e Garapa: caracterização molecular e distribuição de dois retrotransposons com LTR de cana-de-açúcar [Tese]. São Paulo: Instituto de Ciências Biomédicas da Universidade de São Paulo; 2009.

A cana-de-açúcar é uma gramínea de interesse agronômico híbrida e poliplóide e possui um dos genomas mais complexos já estudados. O principal componente dos genomas de gramíneas são os retrotransposons com Longas Terminações Repetidas (LTR), que podem corresponder a mais de $50 \%$ do genoma. A despeito de sua relevância, há pouco conhecimento a respeito do universo de retrotransposons com LTR em cana. Neste contexto, o objetivo deste trabalho foi isolar e caracterizar uma nova família de retrotransposons Copia em cana-deaçúcar, a partir da caracterização genômica e funcional de um cDNA relacionado ao elemento Tnt1, e também compreender a diversidade de retrotransposons com LTR transcricionalmente ativos em cana, com base na análise filogenética de cDNAs provenientes do projeto SUCEST (Sugarcane EST project) relacionados a este grupo de elementos transponíveis. Foi assim isolada uma nova família de retrotransposons de cana, denominada SURE (SUgarcane REtrotransposon). Tratase de um elemento da linhagem Ivana de retrotransposons da superfamília Copia. Apresenta baixo número de cópias, baixa diversidade entre estas cópias, é transcricionalmente ativo em tecidos pouco diferenciados, apresenta polimorfismo de inserção em diferentes variedades de cana e está presente espécies genitoras e espécies relacionadas. $\mathrm{Na}$ análise de dois clones de BAC contendo uma cópia de SURE, o genoma da cana-de-açúcar apresentou grande colinearidade com os genomas de sorgo e arroz nas regiões gênicas. Foram também classificados cDNAs e seqüências completas de retrotransposons com LTR de cana-de-açúcar com base em linhagens evolutivas ubíquas no reino vegetal. A maioria destas linhagens apresenta ao menos um representante em cana. O conjunto de seqüências relacionado a retrotransposons com LTR mais representado no transcriptoma canade-açúcar foi reunido como um novo grupo da superfamília Copia em cana-deaçúcar: Garapa. Trata-se de um elemento largamente distribuído nos cromossomos de cana e com maior variabiliadade que SURE. Dessa forma, SURE e Garapa apresentam-se como duas linhagens diferentes de retrotransposons da superfamília Copia (Ivana e Ale) que apresentam padrões distintos de amplificação no genoma de cana-de-açúcar.

Palavras-chave: Retrotransposon. Cana-de-açúcar. Genômica. Análise transcricional. Análise filogenética. 


\begin{abstract}
Domingues DS. SURE and Garapa: molecular characterization and distribution of two LTR retrotransposons of sugarcane [Doctoral Thesis]. São Paulo: Instituto de Ciências Biomédicas da Universidade de São Paulo; 2009.

Sugarcane is an economically important grass, containing a hybrid and polyploid genome, one of the most complexes studied up to date. The major component of grasses genomes are Long Terminal Repeat (LTR)-retrotransposons, which can correspond to more than $50 \%$ of the genome. Despite of their relevance, little is known about the universe of these elements in sugarcane. In this context, the aim of this work was to isolate and characterize a sugarcane element belonging to a new Copia retrotransposon-family in sugarcane, based on a cDNA-sequence related to a Tnt1 element, and also study the diversity of transcriptional active LTRretrotransposons in sugarcane, based in a phylogenetic analysis of cDNAs from SUCEST (Sugarcane EST project), related to this group of transposable elements. As a result, a new retrotransposon family from sugarcane was identified and named SURE (Sugarcane REtrotransposon). SURE is a member of the Ivana lineage of Copia retrotransposons. SURE has a low copy number within sugarcane genome, and their copies showed few nucleotide polymorphism. SURE retroelements are present in both parental species and other related species to sugarcane. It is transcriptionally active in undifferentiated tissues and they present polymorphic target sites among different sugarcane varieties. The analysis of two BAC clones bearing one copy each of SURE retroelement showed that this two fragments of sugarcane genome have a high sinteny with sorghum and rice genomes in coding regions. Other cDNA-sequences and genomic fragments containing LTR-retroelements were characterized and compared to pre existent in the plant kingdom. The majority of these lineages had at least one sugarcane element. The most representative group of sequences related to LTR retrotransposons present in sugarcane transcriptome was reunited as a new group of Copia superfamily in sugarcane and named Garapa. It comprises elements highly distributed in sugarcane chromosomes and with a higher variability when compared to SURE. Finally, SURE and Garapa represent two distinct lineages of Copia retrotransposons (Ivana and Ale) that had different amplification pattern in the sugarcane genome.
\end{abstract}

Key words: Retrotransposon. Sugarcane. Genomics. Transcriptional analysis. Phylogenetic analysis. 


\section{Introdução}

\subsection{A cana-de-açúcar}

\subsubsection{Aspectos taxonômicos e origem dos cultivares modernos}

A cana-de-açúcar (Saccharum spp) é uma planta monocotiledônea pertencente à família Poaceae (gramíneas), subfamília Panicoideae, tribo Andropogoneae, subtribo Saccharinae. Segundo a classificação taxonômica do complexo Saccharum revisada por Amalraj e Balasundaram (2006), este gênero possui seis espécies: S. officinarum, S. barberi, S. sinense, S. edule, S. robustum e S. spontaneum. São observados dois principais centros de origem do gênero (Grivet, et al., 2004): o Sudeste Asiático, mais especificamente na Ilha da Nova Guiné (S. officinarum, S. edule, S. robustum), e as espécies com origem no Norte da India e da China (S. barberi e $S$. sinense). S. spontaneum seria a espécie com a maior distribuição geográfica, com origem na Índia e estendendo-se da região do Mediterrâneo, passando pela África e chegando até a Nova Guiné. O número cromossômico 2n entre as espécies pode variar de 36 a 170 (Irvine, 1999), e há muitos casos de poliploidia e aneuplodia.

Existem diversas hipóteses a respeito da domesticação da cana, como revisado por diversos autores, como por exemplo: Irvine (1999); Grivet, et al. (2004) e Amalraj e Balasundaram (2006). Postula-se que eventos de hibridização entre Saccharum e gêneros próximos ao da cana, como Miscanthus e Erianthus, possam também ter contribuído para o surgimento das espécies atuais. O conjunto destes gêneros que estariam envolvidos na origem da cana-de-açúcar, cuja compreensão de suas relações filogenéticas é tema de discussão até os dias atuais, como em Hodkinson, et al. (2002) é conhecido por "complexo Saccharum".

Vale também destacar que outras plantas de interesse agronômico apresentam proximidade filogenética à cana-de-açúcar: o milho e o sorgo são também da tribo Andropogoneae; o trigo e o arroz também são gramíneas (família Poaceae).

Os primeiros cultivares de cana utilizados para finalidades agrícolas eram provenientes da espécie $S$. officinarum, rica em açúcar. Estes cultivares tradicionais, 
denominados de canas "nobres", foram a base inicial para o estabelecimento dos cultivares modernos de cana-de-açúcar (Grivet, et al., 2004).

As canas "nobres", embora boas produtoras de açúcar, eram susceptíveis a uma série de doenças. Dessa forma, a partir do final do século XIX, foram iniciados cruzamentos induzidos entre as canas nobres e as demais espécies do gênero Saccharum, notadamente S. spontaneum, a fim de que as variedades com utilidade agronômica ganhassem mais robustez e resistência à doenças. Nesse processo também foram utilizados retrocruzamentos com $S$. officinarum e outros híbridos interespecíficos (Irvine, 1999; Garcia, 2007). O resultado desse processo trouxe efetivos ganhos na produção. Graças à ele, os cultivares atuais de cana-de-açúcar são híbridos interespecíficos, cujas variedades de origem já eram poliplóides e aneuplóides. Baseado em evidências moleculares, D'Hont (2005) estima que os cultivares modernos de cana-de-açúcar sejam octaplóides, nos quais 75 a 85\% dos cromossomos sejam originarios de S. officinarum e 15 a 25\% dos cromossomos tenham origem em S. spontaneum. A Figura 1 representa a organização cromossômica inferida para os cultivares modernos de cana. Avaliações citogenéticas em diferentes cultivares modernos propõem que menos de $5 \%$ dos cromossomos de cana sofreram recombinações e possuem trechos de ambas as espécies genitoras (Cuadrado, et al., 2004; D'Hont, 2005).

Portanto, estes cruzamentos obtiveram êxito em introgredir resistência à doenças, vigor e adaptabilidade. E este processo levou a cana-de-açúcar a ter uma das composições de genoma mais complexas entre as espécies vegetais de interesse agronômico (Grivet e Arruda, 2002). 


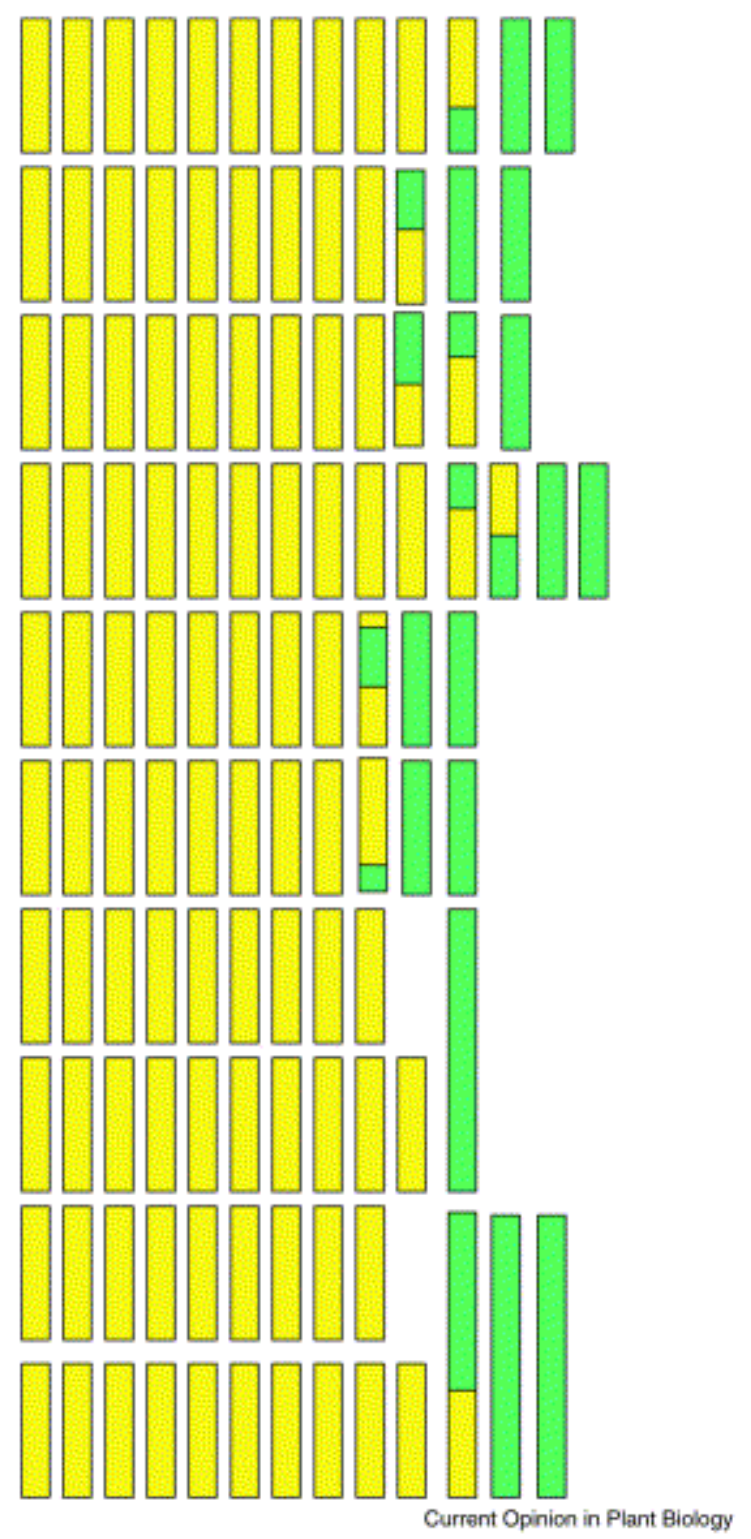

Figura 1 - Organização esquemática do genoma de um cultivar atual de cana-de-açúcar. Cada barra representa um cromossomo; em amarelo estão representadas as regiões provenientes de $S$. officinarum e em verde, as provenientes de $S$. spontaneum. Os cromossomos alinhados na mesma coluna pertencem ao mesmo grupo homeólogo. Dessa forma, ficam ressaltadas a alta polidia, a aneuploidia, a origem bi-parental dos cromossomos (com no mínimo 3/4 herdados de $S$. officinarum), a ocorrência de diferenças estruturais entre os cromossomos de origens distintas e a existência de cromossomos recombinantes interespecíficos. Retirado de Grivet e Arruda, 2002.

\subsubsection{Aspectos econômicos}

A cana é uma das mais importantes culturas tropicais e é utilizada por séculos como fonte produtora de açúcar. Cerca de dois terços do açúcar produzido no mundo é derivado da cana-de-açúcar, que possui cerca de 20 milhões de hectares plantados em regiões tropicais e subtropicais do globo (Menossi, et al., 2008). Mais 
recentemente, a cana também passou a ganhar destaque pelo uso na produção de etanol.

O Brasil é o maior produtor de cana-de-açúcar do mundo, e por conseqüência, de açúcar e etanol derivados de cana. O agronegócio da cana-deaçúcar reúne 6\% dos empregos agroindustriais brasileiros e é responsável por 35\% do PIB e do emprego rural do Estado de São Paulo. A produção da safra brasileira 2006/2007 foi de 426 milhões de toneladas de cana, dos quais 372 milhões foram produzidos no Centro-Sul do país (Cooperativa dos Plantadores de Cana da Zona de Guariba, 2008).

Diversos produtos (além do açúcar e do álcool) são obtidos a partir da cana: bebidas (caldo de cana, cachaça, rum), ração animal, energia, papéis e fármacos (a partir do bagaço), polietileno, estireno, cetona, acetaldeído, poliestireno, ácido acético, éter e acetona (a partir do etanol), fertilizantes (a partir da vinhaça e do vinhoto). Da mesma forma que o petróleo, a cana também oferece uma gama enorme de subprodutos.

Historicamente, o início do cultivo da cana no Brasil deu-se com as expedições de Martim Afonso de Sousa, no século XVI. Com o alto preço do açúcar na Europa à época, o Brasil-colônia teve seu primeiro ciclo econômico baseado na produção de açúcar em engenhos, no Nordeste. Os engenhos tiveram grande importância tanto econômica quanto cultural à esta região e foram inclusive tema relevante da literatura nordestina.

Atualmente, setenta porcento da produção nacional de cana é destinada à produção de etanol (álcool). O produto tem grande procura nacional e internacional, como biocombustível, uma vez que é uma fonte de energia renovável e gerar menos dióxido de carbono que o petróleo em sua queima, sendo assim menos poluente.

O Brasil é pioneiro na implementação de automóveis que utilizam etanol de cana como combustível. Desde a década de 1970, existem no mercado carros movidos à álcool. Com o desenvolvimento dos motores bicombustíveis, que aceitam tanto gasolina como álcool como combustível, houve um grande impulso para o consumo do etanol. Em 2008, 87,6\% dos carros vendidos no Brasil eram bicombustíveis (Moreira, 2009).

Além da pressão do mercado brasileiro para uma maior produção de etanol, outros países do mundo passaram também a utilizar o etanol como fonte de energia. 
Estima-se que, em função disso, a produção brasileira de cana-de-açúcar deverá dobrar até 2015, para assim atender à demanda (Torquato, 2006).

Em razão da importância econômica da cana, há uma grande motivação para o desenvolvimento de pesquisas sobre todas as etapas que envolvem a agroindústria dessa cultura. Devido ao papel relevante na economia agroindustrial brasileira, houve no país nas ultimas décadas um grande incentivo às pesquisas com cana. Nesse cenário, surgiram diversos trabalhos que buscam investigar diversos aspectos biológicos da cana-de-açúcar, dos quais aqui destacamos a melhor compreensão dos aspectos genômicos desta planta.

\subsubsection{O genoma da cana-de-açúcar}

As abordagens usuais de estudos genéticos - que normalmente utilizam como ponto de partida genomas diplóides - não são as ideais para compreender a complexidade do genoma da cana-de-açúcar, por se tratar de um genoma poliplóide e aneuplóide. Wu, et al. (1992) e Qu e Hancock (2001), por exemplo, fazem uma série de considerações teóricas a respeito das particularidades na utilização de marcadores moleculares para análise genética em genomas poliplóides.

Dessa forma, uma das primeiras preocupações no que diz respeito ao material genético da cana foi a determinação da ploidia e do conjunto básico das espécies do gênero Saccharum. Para o estabelecimento definitivo do número $2 \mathrm{n}$ e $\mathrm{x}$ de cromossomos de S. officinarum e S. spontaneum, foi fundamental a utilização de ferramentas de citogenética molecular. D’Hont, et al. (1998) determinou por estas técnicas que o número cromossômico básico de $S$. officinarum é $x=10$ e de $S$. spontaneum é $x=8$, assim esclarecendo as diferenças de ploidia, que vão de 5 a 16 (Grivet e Arruda, 2002).

Estima-se que um conjunto básico de cromossomos de cana corresponda a entre 760 e 926Mbp (Menossi, et al., 2008). Embora seja consideravelmente maior que o do arroz, que é uma espécie-modelo de monocotiledôneas (389Mbp), o tamanho é similar ao do sorgo (760Mbp) (Menossi, et al., 2008), que entre plantas com interesse agronômico é a mais próxima filogeneticamente à cana-de-açúcar.

Uma das primeiras estratégias moleculares utilizadas para o estudo do genoma da cana-de-açúcar foi o estabelecimento de mapas genéticos de ligação, a partir de diferentes marcadores moleculares. Estes foram incialmente conduzidos 
nas espécies genitoras de cana, utilizando marcadores RFLP, RAPD e AFLP como nos trabalhos de Al-Janabi, et al. (1993), Da Silva, et al. (1993), D'Hont, et al. (1994) e Mudje, et al. (1996). Estudos utilizando marcadores moleculares foram capazes inclusive de inferir, de maneira correta, o número básico de cromossomos de Saccharum spontaneum (Da Silva, et al., 1993). Posteriormente, foram desenvolvidos mapas genéticos para os cultivares híbridos atuais (Grivet, et al., 1996; Ming, et al., 2002), dos quais foi possível inclusive compreender a diversidade genética entre diferentes variedades atuais (Lima, et al., 2002). A comparação destes mapas de cana com os de outras gramíneas reveleram sintenia para alguns locus (Dufour, et al., 1997; Guimarães, et al., 1997; Ming, et al., 1998), embora para outros o mapeamento baseado em sintenia trouxe dificuldades (Asnaghi, et al., 2000).

A localização dos primeiros genes e/ou regiões genômicas de interesse agronômico para a cana-de-açúcar foram baseadas no mapeamento genético. Foram assim mapeados um gene relacionado a resistência à ferrugem em cana (Asnaghi, et al., 2000), QTLs relacionados à quantidade de açúcar (Ming, et al., 2001) e à produtividade em cana (Hoarau, et al., 2002). Ainda que tenham sido obtidos resultados positivos, a complexidade do mapeamento genético em cana torna pouco atrativo este método para o estudo do genoma dessa planta.

Com o desenvolvimento de uma série de projetos de seqüenciamento em larga escala, esta estratégia apresentou-se como uma boa alternativa para 0 conhecimento do repertório de genes da cana. A partir desse ponto de vista é que foi desenvolvido o Sugarcane EST Project (SUCEST), desenvolvido majoritariamente no estado de São Paulo, com o objetivo de conhecer melhor os genes da cana-deaçúcar. Uma vez que o seqüenciamento completo do genoma da cana seria uma tarefa laboriosa, foi adotada uma estratégia transcriptômica: foram sequenciados parcialmente mais de 237000 RNAs mensageiros de cana (Vettore, et al., 2003). Estes transcritos foram provenientes de 26 bibliotecas de cDNA, provenientes de diversos tecidos, estágios e variedades de cana-de-açúcar, cuja descrição detalhada encontra-se em Vettore, et al. (2001). O agrupamento destas seqüências resultou em um catálogo com cerca de 33000 genes únicos, que provavelmente representam mais de 90\% dos genes da cana-de-açúcar (Vettore, et al., 2003), dos quais cerca de $70 \%$ apresentam um correspondente em Arabidopsis thaliana e mais de $81 \%$ apresentam um homólogo em arroz (Vincentz, et al., 2004). 
Além de uma caracterização in silico dos genes únicos hipotéticos de cana, detalhada em Vettore, et al. (2003) e Vincentz, et al. (2004), o volume 24 da revista "Genetics and Molecular Biology" (2001) foi dedicado aos resultados da análise manual do transcriptoma da cana-de-açúcar.

Estes trabalhos serviram de base para a caracterização em cana de genes com as mais variadas funções: proteínas de defesa a fitopatógenos (Soares-Costa, et al., 2002), fatores de transcrição (Nogueira, et al., 2005), genes relacionados à via de reparo de DNA (Scortecci, et al., 2007), entre outros.

Dentre as diferentes categorias funcionais na qual foram classificados os genes expressos de cana, Rossi, et al. (2001) focou-se na identificação de elementos transponíveis (TEs, do inglês transposable elements) representados no banco de dados do projeto SUCEST. Os TEs aparecem como a $2^{\mathrm{a}}$ principal categoria entre as entidades genômicas de rápida evolução em cana (Vincentz, et al., 2004).

Utilizando como ponto de partida o banco de dados SUCEST, foi possível uma análise detalhada de algumas famílias de TEs, como em Rossi, et al. (2004), Saccaro Júnior, et al. (2007) e De Jesus (2007), bem como avaliar o padrão transcricional destes elementos (Araújo, et al., 2005). O presente trabalho também insere-se nesse contexto, empregando o projeto SUCEST e seus desdobramentos como motivação incial para a compreensão de um grupo específico de elementos transponíveis em cana-de-açúcar.

\subsection{Elementos Transponíveis}

Os elementos transponíveis são seqüências genômicas repetitivas que são capazes de se movimentar (se transpor) de uma região cromossômica para outra. Neste processo, podem ou não replicarem-se (Bowen e Jordan, 2002). Constituem uma fração bastante significativa dos genomas eucariotos: em humanos, representam 45\% do genoma e em algumas espécies vegetais podem ultrapassar $80 \%$ do genoma (Meyers, et al., 2001).

A primeira pesquisadora a inferir a existência dos TEs foi Barbara McClintock, ao estudar mutantes de milho com segregações aberrantes para alguns loci. Um deles é o padrão da coloração do endosperma da semente do milho, que seria alterada por dois loci capazes se transpor de uma região cromossômica para outra 
ao longo das divisões celulares do endosperma (McClintock, 1950), o que explicaria o padrão variegado deste fenótipo. Estes loci foram batizados de Ac (Activator) e Ds (Dissociator, capaz de causar quebras cromossômicas em algumas regiões). Mais tarde, seria observado que, neste caso, um elemento transponível interrompe um gene envolvido na biossíntese de antocianinas. A Figura a seguir exemplifica o que ocorre no fenótipo variegado do endosperma de sementes de milho.

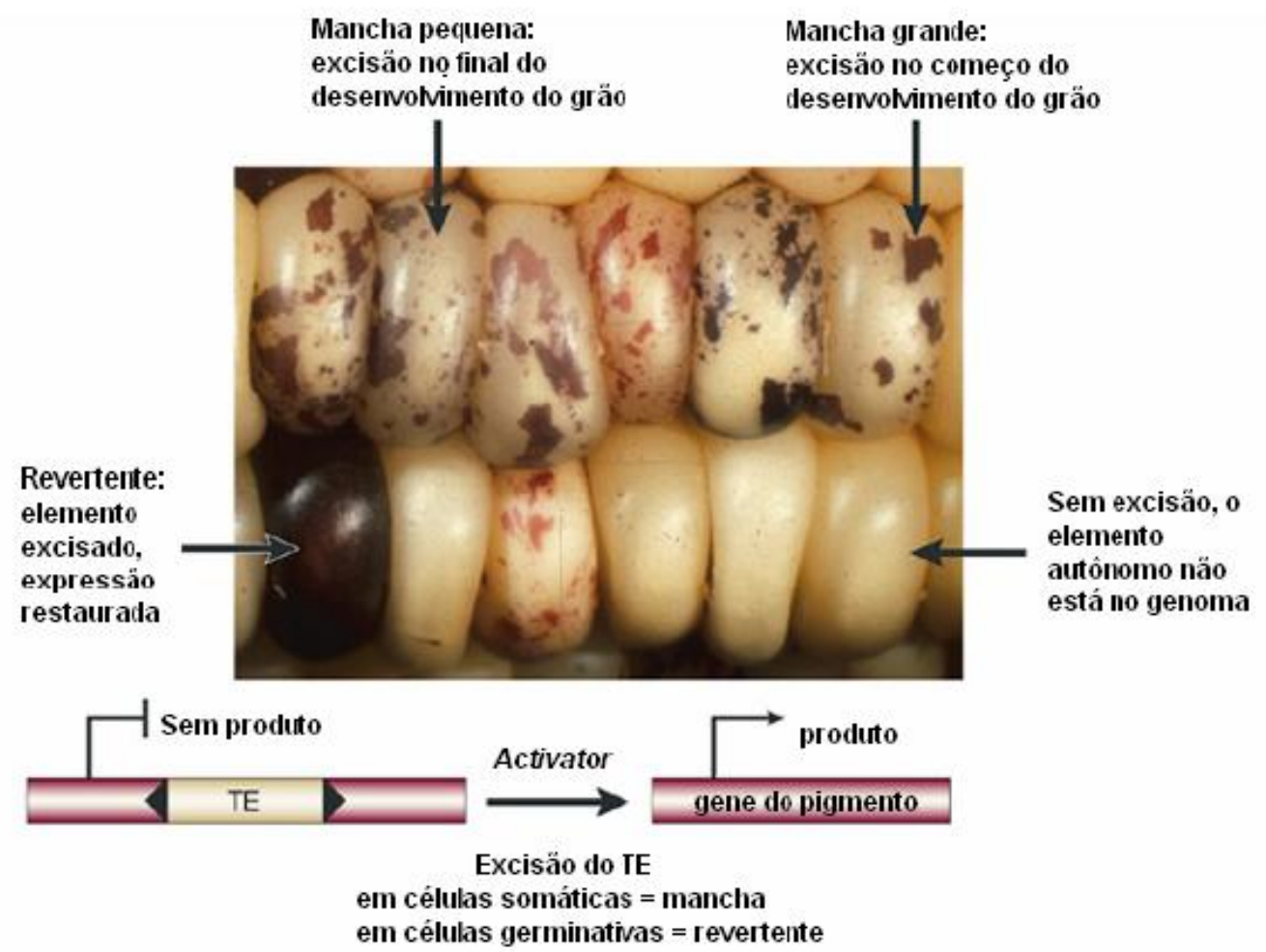

Figura 2 - Diferentes fenótipos observados em grãos de milho devido à ação de TEs. A instabilidade dos fenótipos se deve à inserção ou excisão do elemento em um gene que codifica uma enzima que participa da rota de biossíntese do pigmento antocianina. Setores revertentes (com pigmento) resultam da excisão do elemento em células da camada de aleurona. O tamanho do setor reflete o momento durante o desenvolvimento onde a excisão aconteceu. Adaptado de Feschotte, et al. (2002).

Apenas na década de 1960 foi realizada a primeira caracterização molecular de um elemento transponível, em Escherichia coli (Jordan, et al., 1967), graças ao florescimento da Biologia Molecular a partir de modelos bacterianos. A partir da década de 1970, tomou corpo a idéia de que os TEs estão presentes em praticamente todos os eucariotos conhecidos, o que culminou com o Prêmio Nobel de Medicina concedido à Barbara McClintock em 1983. 
Mais tarde, Bhattacharyya, et al. (1990) demonstrou inclusive que o alelo recessivo responsável pelo fenótipo rugoso observado por Mendel em sementes de ervilha é resultado de uma inserção de um elemento transponível em uma enzima responsável pela concatenação de moléculas de amido. Esta inserção acaba gerando uma enzima não-funcional, que diminui o acúmulo de amido em sementes de ervilha.

Em termos evolutivos, a função dos elementos transponíveis é amplamente debatida. Doolittle e Sapienza (1980), em um artigo clássico, colocaram os TEs como "parasitas genômicos", uma vez que não possuiriam uma função fenotípica observada e possuem uma estratégia própria de "sobrevivência genômica", replicando-se a si mesmos ou constamentemente mudando sua localização genômica. Como não teriam uma função evolutiva clara, estariam apenas voltados à sua auto-preservação. Em um contexto também influenciado pela teoria do "gene egoísta" de Dawkins (1976), estudos evolutivos a respeito sobre como os TEs influenciariam seu genoma hospedeiro acabaram ficando em segundo plano.

No entanto, as evidências moleculares, sobretudo decorrentes dos grandes projetos de seqüenciamento genômico iniciados a partir dos anos 1990, demonstraram que muitas vezes os TEs podem ser "co-optados" pelo genoma, para a realização de funções celulares. Nesse sentido, Biémont e Vieira (2006) revisam a função dos TEs como força relevante na evolução dos organismos; Feschotte (2008) exemplifica diversas formas nas quais um TEs influencia na regulação gênica, com especial destaque à domesticação de TEs, ou seja, a perda da capacidade de transposição de um TE e sua conversão em um gene de função celular algumas vezes indispensável para a sobrevivência de um organismo.

Cada vez mais fica claro que, embora existam TEs cuja função evolutiva não é evidente, é muito simplista pensar que os elementos transponíveis não contribuíram de maneira nenhuma ao funcionamento celular. Já são bem descritos na literatura diversos exemplos nos quais os TEs estão envolvidos no desempenho de funções relevantes para o organismo: em Drosophila, a manutenção dos telômeros é realizada por dois TEs, HeT-A e TART, que se transpõem exclusivamente na extremidade dos cromossomos (conforme revisado por Pardue, et al., 2005); a recombinação do tipo $V(D) J$, feita pelos genes RAG1 e RAG2, responsável pela geração das imunoglobulinas, também está relacionada à processos de transposição (Zhou, et al., 2004). Em Arabiposis thaliana, genes 
derivados de transposases estão relacionados à processos de desenvolvimento vegetal (Bundock e Hooykaas, 2005) e à respostas da planta à luz (Hudson, et al., 2003; Lin, et al., 2007). Fragmentos de TEs também podem também fazer parte de proteínas em diferentes organismos, de vertebrados a plantas (Wu, et al., 2007; Lopes, et al., 2008).

Portanto, além de questões inerentes à sua larga distribuição nos organismos vivos, questionamentos relacionados à funções celulares de TEs ganham importância na Biologia Molecular.

\subsubsection{Classificação e Estrutura de Elementos Transponíveis}

A primeira classificação proposta para os elementos transponíveis, que é a mais amplamente conhecida e utilizada, é a proposta por Finnegan (1989). Ela divide os TEs de acordo com seu intermediário de transposição: RNA (retrotransposons ou elementos de classe I) ou DNA (elementos de classe II ou transposons de DNA). O mecanismo de transposição dos elementos de classe I seria o de "copia e cola" e o dos elementos de classe II "corta e cola" (Finnegan, 1989). Posteriormente, observou-se que eventualmente alguns elementos da classe Il podem também "copiar e colar".

Com o enorme aumento da caracterização de elementos transponíveis, conseqüência dos projetos de seqüenciamento em larga escala, foram descobertos uma série de TEs que não necessariamente encaixam-se em uma das duas classes. Em função disso, Curcio e Derbyshire (2003) propuseram uma nova classificação, baseada nas propriedades enzimáticas da proteína envolvida no processo de transposição. Esta classificação, no entanto, requer o conhecimento de características dos elementos transponíveis que pesquisadores que não são especialistas no assunto estão pouco familiarizados.

Em razão disso, com o intuito de facilitar a anotação de TEs em projetos de grande escala, normalmente realizados por não-especialistas no assunto, Wicker, et al. (2007) propõem um "sistema de classificação unificado para elementos transponíveis de eucariotos", no qual é proposto um "protocolo" para a anotação de elementos transponíveis. O sistema de classificação de TEs proposto por Wicker, et al. (2007) concilia a divisão "clássica" dos elementos transponíveis com critérios enzimáticos. Embora esta classificação tenha sido colocada em xeque pela equipe 
mantenedora de uma importante base de dados de elementos repetitivos no genoma (Kapitonov e Jurka, 2008), o trabalho de Wicker, et al. (2007) propõe critérios objetivos para a anotação de TEs. Desse modo, ele será o ponto de referência na presente tese para as análises aqui colocadas posteriormente.

As tradicionais "classes" de TEs são subdividas por Wicker, et al. (2007) em Subclasses, Ordens e Superfamílias. Elas estão mais detalhadas na Figura a seguir:

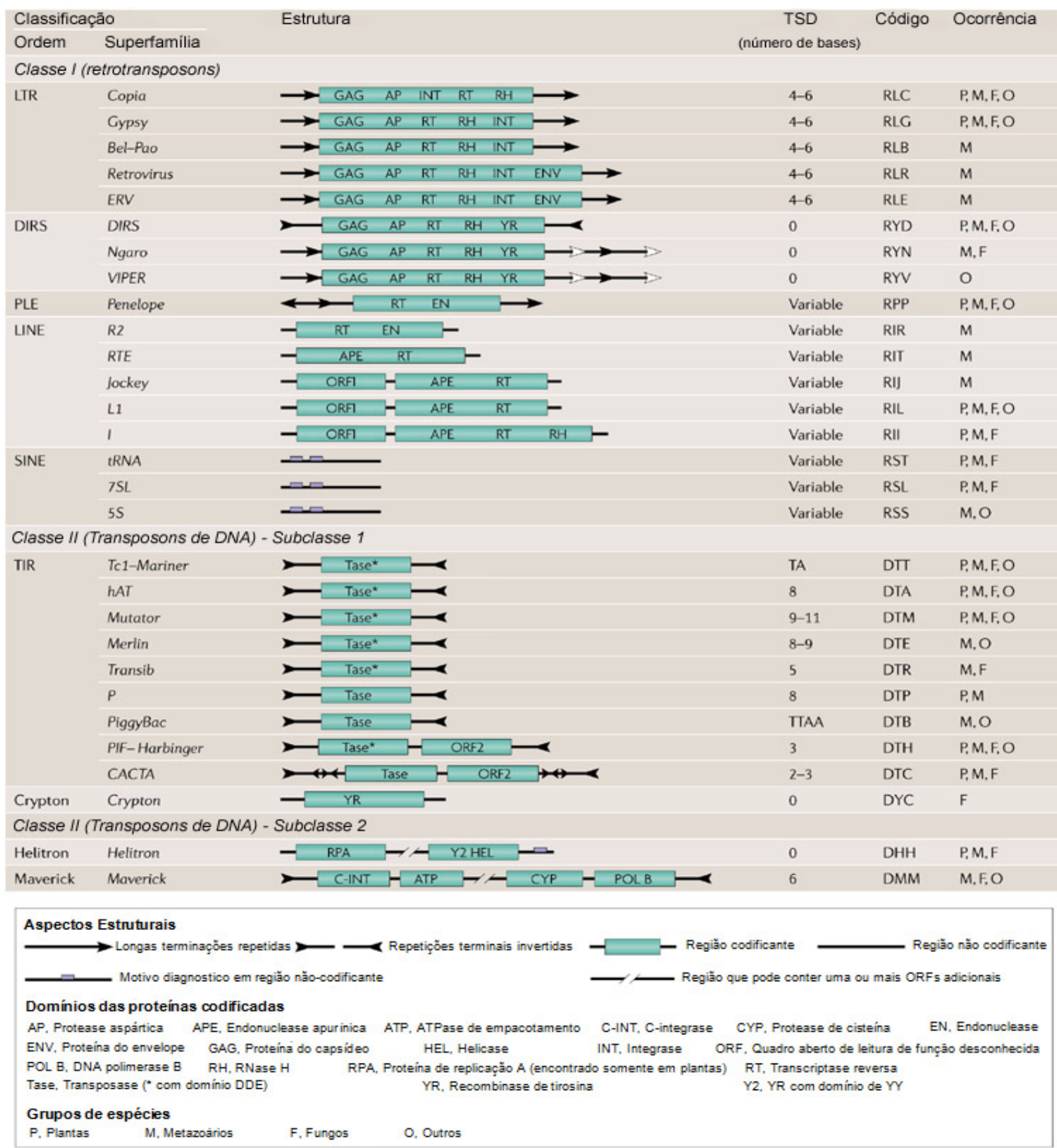

Figura 3 - Sistema de classificação proposto para elementos transponíveis (TEs). Traduzido de Wicker, et al. (2007). 
A estrutura dos TEs disposta na Figura 3 representa, com exceção dos SINEs, apenas elementos autônomos, ou seja, os TEs que seriam capazes de promoverem sua própria transposição. Vale lembrar que os elementos nãoautônomos (que dependem de um elemento autônomo para a transposição) representam também fração importante do genoma dos eucariotos. A principal categoria de TEs não-autônomos são os MITEs (em inglês, Miniature Invertedrepeat Transposable Elements) - elementos pequenos, de 300 pares de base (pb) ou menos). São derivados de grandes deleções em transposons da Classe II, nos quais restaram apenas as TIRs e porções pequenas da região codificante (muitas vezes degeneradas). Além dos SINEs, existem outros retrotransposons nãoautônomos, que serão discutidos posteriormente.

A presente tese tem foco apenas nos retrotransposons com LTR presentes em plantas, ou seja, os da superfamílias Copia e Gypsy.

\subsubsection{Retrotransposons com LTR - Superfamílias Copia e Gypsy: aspectos gerais e estrutura molecular}

Estas duas superfamílias fazem parte das originalmente citadas na classificação proposta por Finnegan (1989), e são as únicas distribuídas em todos os eucariotos (Wicker, et al., 2007). Possuem características estruturais muito semelhantes aos retrovírus, inclusive com a ocorrência de algumas famílias de elementos que codificam uma proteína semelhante a proteína env, responsável pela capacidade de infecção dos retrovírus e ainda pouco estudada em retrotransposons.

Em plantas, são mais abundantes os retrotransposons com LTRs, enquanto nos vertebrados são mais comuns os retrotransposons sem LTR. Para efeito de comparação, enquanto existem catalogados em arroz mais de 5000 loci relacionados a retrotransposons com LTRs, apenas 34 estão relacionados a retrotransposons sem LTR (Jiao e Deng, 2007). No seu processo de mobilização, os retrotransposons não sofrem excisão e reinserção em outro ponto do genoma; sua transposição ocorre com a inserção de uma nova cópia no genoma, reverso transcrita a partir de um mRNA (Kumar e Bennetzen, 1999). Logo, a seqüência original permanecerá no genoma do hospedeiro e assim pode haver um aumento exponencial do número de cópias do elemento. 
Este mecanismo replicativo parece estar relacionado às diferenças de tamanho de genoma entre as espécies vegetais. É comum que algumas espécies vegetais tenham como componente majoritário do genoma algumas famílias de retrotransposons com LTR. Este fenômeno já foi relatado em cevada (Suoniemi, et al., 1996), em algodão (Hawkins, et al., 2006) e em espécies do gênero Oryza (Piegu, et al., 2006). Na maioria destes casos, observa-se inclusive que a "explosão" do número de cópias é recente em termos evolutivos, ocorrida há menos de 3 milhões de anos.

As superfamílias Copia e Gypsy recebem os mesmos nomes dos elementos inicialmente caracterizados em Drosophila melanogaster, e estão respectivamente relacionados com os elementos Ty1 e Ty3 de levedura (Griffiths, et al., 2001). Os elementos Gypsy têm uma organização mais próxima a dos retrovírus e diferenciamse do grupo Copia, por apresentar o domínio da transcriptase reversa anterior ao domínio da integrase. Ambos os grupos de retrotransposons com LTRs são amplamente distribuídos no reino vegetal (Voytas, et al., 1992; Suoniemi, et al., 1998).

Embora apenas os genes gag e pol sejam necessários e suficientes para um evento de transposição, podem ser observadas outras organizações genômicas nos retrotransposons vegetais com LTRs. Existem retrotransposons com quadros abertos de leitura extras na mesma posição em que encontra-se o gene env nos retrovírus. Embora elementos desse tipo pareçam também estar dispersos por todo o reino vegetal (Vicient, et al., 2001a; Wicker e Keller, 2007), existem poucos elementos com env completamente caracterizados, como o retrotransposon SIRE-1 de soja (Laten, et al., 1998) e Tat-1, de Arabidopsis thaliana (Wright e Voytas, 1998). Algumas vezes, a ORF "extra" possui função desconhecida, caso do retrotransposon Grande1 de milho (Martinez-Izquierdo, et al., 1997), que possui um quadro de leitura putativo em posição antisenso em relação à transcrição do retrotransposon.

Como observa-se na Figura 4, a LTR dos retrotransposons tipo Copia e Gypsy é subdividida em 3 regiões: U3, R e U5. A região U3 da LTR contém a seqüência promotora da transcrição do elemento, conforme demonstrado para o retrotransposon Tnt1 de tabaco (Vernhettes, et al., 1997) e Retrolyc1 (Araújo, et al., 2001). 


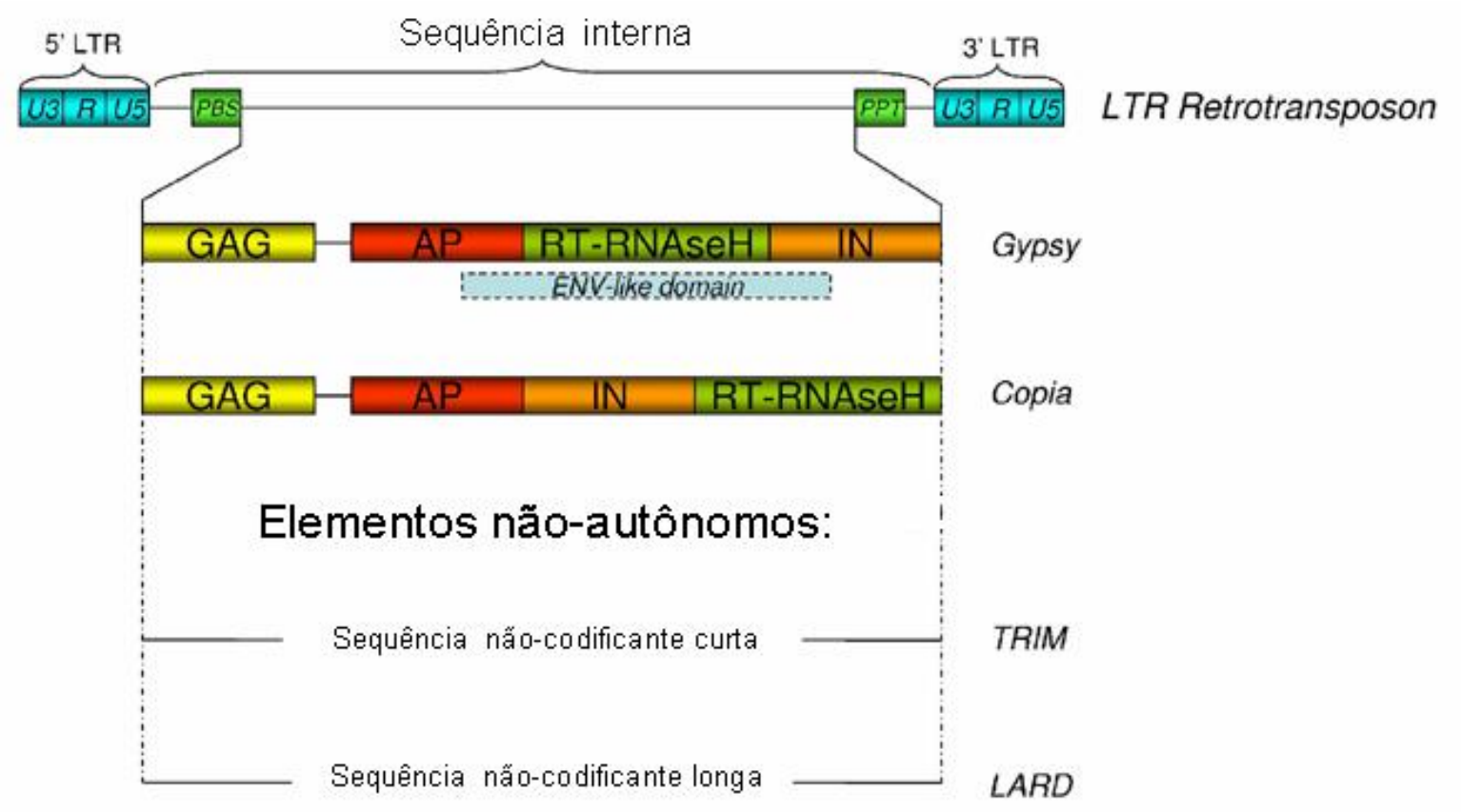

Figura 4 - Estruturas gerais dos retrotransposons com LTRs autônomos e não-autônomos. Retirado de Sabot e Schulman (2006).

Os domínios funcionais codificados por retrotransposons com LTRs são constituídos por dois genes: Gag e pol, que podem ser transcritos em um ou mais quadros abertos de leitura (open reading frames - ORFs) (Gao, et al., 2003). O domínio Gag é responsável por uma proteína semelhante ao capsídeo viral, que está envolvida na maturação e "empacotamento" do RNA e proteínas do retrotransposon a ser posteriormente integrado ao genoma. O gene pol (poliproteína) é responsável por codificar a transcriptase reversa (RT - reverse transcriptase), RNAse $\mathrm{H}$, integrase (IN) e uma protease aspártica (AP - aspartic protease). As duas primeiras enzimas são necessárias para replicação e transposição, e a integrase permite que o retrotransposon já em forma de DNA possa inserir-se em uma nova região cromossômica. A protease é responsável pela maturação dos diferentes domínios citados da poliproteína.

Os retrotransposons com LTRs não-autônomos são provavelmente derivados de mecanismos decorrentes de uma força de "compensação" para diminuir o impacto do aumento do genoma provocado pela amplificação dos retrotransposons com LTR. Conforme revisado por Vitte e Panaud (2005), a recombinação entre retrotransposons presentes em grande número de cópias geram elementos dos quais apenas restaram as LTRs ("solo-LTRs") ou derivados de diferentes tamanhos. 
Estes TEs mobilizados em trans por elementos funcionais. Eles contém algumas estruturas básicas como as LTRs, o sítio de ligação do iniciador ("Primer Binding Site" - PBS) à 5' e uma região de polipurinas ("Polypurine Tract" - PPT) à 3'; no entanto, perderam sua capacidade codificante. São divididos em duas classes principais: grandes derivados de retrotransposons (Large Retrotransposon Derivatives - LARDS) (Kalendar, et al., 2004) e retrotransposons de repetição terminal em miniatura (terminal-repeat retrotransposons in miniature - TRIMs).

Os primeiros possuem alguns milhares de base $(\mathrm{kb})$ em extensão: no caso do LARD Dasheng, de arroz, este tamanho varia de 5.5 a $8 \mathrm{~kb}$ e existem evidências que Dasheng é mobilizado pelo retrotransposon RIRE2 (Jiang, et al., 2002). Já os TRIMs até hoje conhecidos possuem no máximo cerca de 600 pares de base (bp), e muitas vezes são encontrados em regiões promotoras e íntrons de genes, o que indica um potencial papel relevante na reestruturação dos genomas vegetais (Witte, et al., 2001; Havecker, et al., 2004).

\subsubsection{Ciclo de vida e localização cromossômica de retrotransposons das superfamílias Copia e Gypsy}

Dada à semelhança na estrutura genômica entre os retrotransposons vegetais com LTR e os retrovírus, é possível dessa forma deduzir um "ciclo de vida" dos retrotransposons no genoma vegetal. Na Figura 5, estão detalhadas as etapas necessárias para a amplificação de um retrotransposon autônomo.

Com isso, fica evidenciada a importância da tradução balanceada entre Gag e Pol para que ocorra um evento de transposição, já que para o empacotamento de um único cDNA correspondente a uma nova copia de retrotransposon são necessárias vários peptídeos da Gag. Gao, et al. (2003), ao discutir sobre a importância do "excesso de Gag" para a ocorrência de transposição de um retrotransposon, mostra que ainda não são claros os mecanismos que estão envolvidos na produção deste excesso, sobretudo nos elementos Copia, que apresentam uma única ORF codificando Gag e Pol. 


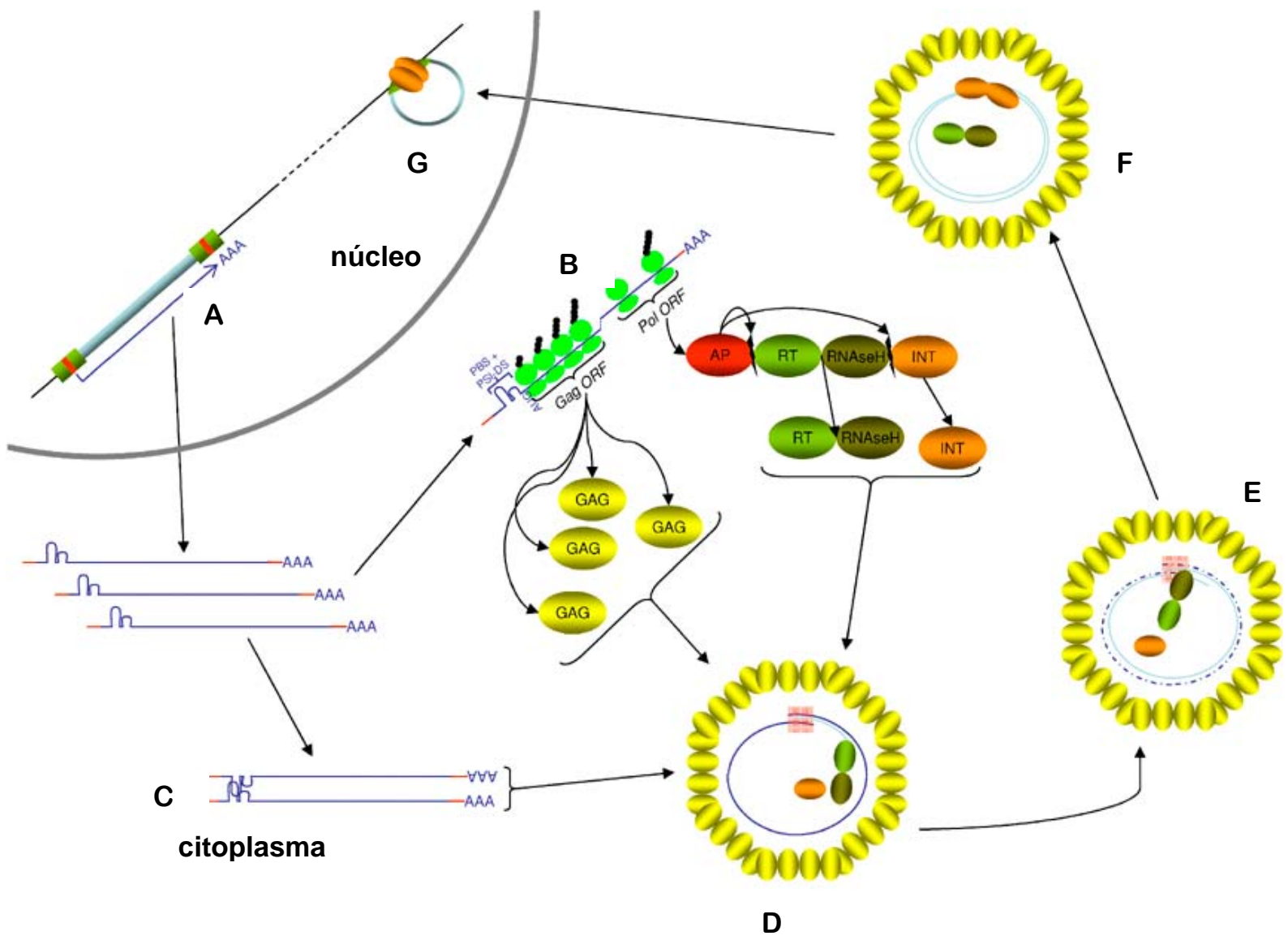

Figura 5 - "Ciclo de vida teórico" de um retrotransposon com LTR. Legenda: (A) Transcrição do mRNA, iniciando da região 5’ R até a região 3’ R; (B) Tradução e sintese proteica (nos elementos ativos) em $\mathrm{Gag}$ e $\mathrm{Pol}$; a $\mathrm{Pol}$ é posteriormente clivada pela protease em AP (protease aspártica), RT-RNAseH e IN (integrase); (C) Dimerização do RNA antes ou durante o empacotamento; (D) Empacotamento do RNA e início da transcrição reversa. As Gags polimerizam-se para formar a partícula semelhante a vírus (VLP - virus-like particle), na qual a transcrição reversa é feita pela proteína de dupla função RT-RNaseH. Dessa forma, a primeira fita do cDNA é feita usando o RNA empacotado como molde; (E) Degradação do molde de RNA e início da síntese da segunda fita de cDNA; (F) Finalização da síntese do cDNA dupla fita e ligação da IN as LTRs. (G) Quebra da dupla fita e integração da nova cópia em uma nova região genômica. Retirado de Sabot e Schulman (2006).

No estudo transcricional por RT-PCR do elemento tipo Copia CIRE1 (RicoCabanas e Martínez-Izquierdo, 2007) identificou-se uma banda muito mais forte de transcrição de um fragmento da transcriptase reversa (RT) do que da Gag, o que poderia ser interpretado como uma 'regulação negativa' da Gag visando diminuir a transposição deste elemento, ou que elementos defectivos, que apresentam apenas a $\mathrm{Pol}$, estariam transcricionalmente ativos.

Como os elementos de transposição constituem uma porcentagem bastante representativa dos genomas vegetais, a distribuição cromossômica destes, sobretudo dos retrotransposons, já foi investigada em diversas espécies vegetais por técnicas de citogenética molecular, como a Hibridação por Fluorescência In Situ 
(Fluorescence In Situ Hybridization - FISH). Conforme revisado por Kumar e Bennetzen (1999), a distribuição cromossômica de retrotransposons em cromossomos metafásicos pode ser uniforme ou não, o que depende da espécie e da família que está em análise. Em espécies da famíia Triticaceae, Belyayev, et al. (2001) observou um padrão de retrotransposons preferencialmente agrupados em algumas regiões cromossômicas; no entanto, a organização genômica de retroelementos em Brassica oleracea (Alix, et al., 2005) não observou uma distribuição clusterizada de retroelementos, já que estes encontravam-se dispersos ao longo de todo o cromossomo.

$\mathrm{Na}$ literatura existem exemplos de famílias de retroelementos com eventual sítio de inserção preferencial: em Allium cepa há uma família de retrotransposons preferencialmente localizada em telômeros (Pearce, et al., 1996). Em gramíneas, há um grupo de retrotransposons do tipo Gypsy presentes exclusivamente em centrômeros (Miller, et al., 1998). Muitas vezes, a localização preferencial de um elemento é "mascarada" por ele ter sido mudado de posição em eventos de recombinação, mas de maneira geral, pode-se encontrar elementos transponíveis ao longo de todo o cromossomo (Heslop-Harrison, et al., 1997; Kumar e Bennetzen, 1999).

O sequenciamento de grandes fragmentos genômicos de bibliotecas de BAC também identificou elementos distribuídos em regiões intergênicas (SanMiguel et al., 1996) e o uso desse tipo de fragmento como sonda em experimentos de FISH também já permitiu a localização genômica de regiões cromossômicas ricas em elementos de transposição em trigo (Zhang, et al., 2004).

Portanto, ainda não há uma regra geral para a distribuição cromossômica de retrotransposons, uma vez que isto pode variar muito em função da espécie e da família de elementos estudada.

\subsubsection{Expressão e sítios de inserção de retrotransposons com LTR}

A transcrição de um retrotransposon não significa necessariamente que ele é transposicionalmente ativo, ou seja, que ele esteja efetivamente inserindo-se em uma nova região do genoma. Por conta disso, o número de retrotransposons com LTR com caracterização detalhada de sua transposição é relativamente pequeno, se for levado em conta a representatividade deste grupo de seqüências no genoma 
eucarioto, especialmente dos vegetais. Um número pequeno de famílias de retroelementos em plantas tem sua atividade de transposição demonstrada, entre os quais destacam-se o elemento Tnt1 de fumo (Grandbastien, et al., 1989) e Tos17 de arroz (Hirochika, et al., 1996). Nestes dois casos, os eventos de transposição estão relacionados a algum tipo de estresse, como a indução de cultura de células - calos ou protoplastos. A indução de calos também provoca a atividade transposicional de retrotransposons com LTR em batata-doce (Tahara, et al., 2004) e Lotus japonicus (Fukai, et al., 2008).

De maneira geral, o nível transcricional de elementos transponíveis é baixo para a maioria das famílias, em condições fisiológicas (Jiao e Deng, 2007). São poucas as famílias de retrotransposons com LTR que apresentam transcrição ubíqua (Madsen, et al., 2006; Jiao e Deng, 2007). Análises transcricionais baseadas em banco de ESTs evidenciam que, embora sejam componentes predominantes no genoma vegetal, seqüências relacionadas a retrotransposons com LTR correspondem a um percentual baixo no total de transcritos (Meyers, et al., 2001; Echenique, et al., 2002; Vettore, et al., 2003; Lopes, et al., 2008).

A maioria dos elementos transponíveis vegetais são hipermetilados quando comparados à genes de função celular (Rabinowicz, et al., 2003), o que seria a provável razão da baixa atividade transcricional destes elementos. Mecanismos de metilação induzidos por pequenos RNAs provavelmente estão também envolvidos no silenciamento de elementos transponíveis (Vastenhouw e Plasterk, 2004; Fukai, et al., 2008), e estas evidências ficam reforçadas pela capacidade de codificação de pequenos RNAs com origem em elementos transponíveis (Piriyapongsa e Jordan, 2008).

Já foi demonstrado que há uma relação entre heterocromatina e regiões genômicas altamente metiladas em plantas (Martienssen e Colot, 2001). Assim sendo, torna-se dedutível que boa parte dos retrotransposons com LTR concentrase em regiões heterocromáticas. Em Arabidopsis thaliana, de fato é observada uma concentração de retrotransposons com LTR em regiões pericentroméricas e heterocromáticas (Pereira, 2004).

Em levedura, que é um modelo bastante estudado para o estudo de transposição de retroelementos in vivo, é observado de maneira mais evidente uma inserção direcionada de retrotransposons. O elementos Ty1 e Ty3 inserem-se preferencialmente na proximidade de genes de tRNA e/ou transcritos pela RNA 
polimerase III (conforme revisado por Craig, 1997) e o elemento Ty5 insere-se em regiões teloméricase de cromatina "silenciada" (Zou, et al., 1996).

Recentemente, foi demonstrada a inserção específica dos retrotransposons com chromodomain em regiões de heterocromatina (Gao, et al., 2008). Boa parte dos retrotransposons do grupo Gypsy possuem chromodomain, que está presente na porção C-terminal dos retrotransposon desse grupo. O chromodomain corresponde a uma seqüência de 40 a 50 aminoácidos que pode interagir com diversos alvos, como proteínas, RNA e DNA (Brehm, et al., 2004). Entre um dos principais "parceiros" dos chromodomains estão os resíduos metilados das histonas (Gao, et al., 2008), o que levaria a inserção destes elementos em regiões heterocromáticas.

Para os retrotransposons Copia, há uma distribuição de inserção mais variável e um padrão menos claro, embora em Arabidopsis seja vista uma concentração maior de elementos desse grupo em regiões pericentroméricas (Pereira, 2004). É possível que o maior nível de metilação e concentração de heterocromatina nessas regiões leve à esta concentração.

\subsubsection{Análise filogenômica de retrotransposons com LTR em plantas}

Durante muito tempo, a disponibilidade de seqüências genômicas em quantidade era um limitante na análise evolutiva de retrotransposons. O trabalho clássico de Xiong e Eickbush (1990), que partiu de 82 seqüências de retroelementos de diferentes organismos, definiu 7 regiões conservadas da transcriptase reversa (RT). Este trabalho foi pioneiro em compreender a relação entre retrovírus e retroelementos, a partir dos dados existentes à época.

Desde então, conforme destaca Wicker, et al. (2007), a enorme maioria dos trabalhos que procuravam entender especificidades evolutivas dos TEs focavam-se em uma espécie ou em um pequeno grupo de espécies próximas. Isso causava a não-resolução perfeita de linhagens evolutivas: por exemplo, Matsuoka e Tsunewaki (1999) encontraram 4 linhagens evolutivas de retrotransposons do tipo Copia em gramíneas; no entanto, um número substancial seqüências apresentadas no trabalho não se encaixavam em nenhum dos grupos propostos.

Somente a partir da disponibilidade de genomas completos surgiram na literatura trabalhos que investigaram com mais detalhe as relações evolutivas 
internas de cada grupo de TEs. No caso dos retrotransposons com LTR em plantas, os primeiros trabalhos de comparação em larga escala surgiram a partir da análise do genoma de Arabidopsis thaliana. Marín e Lloréns (2000) propõem 9 diferentes linhagens de retrotransposons do tipo Gypsy com base na filogenia da RT e Terol, et al. (2001) propõem 6 grupos evolutivos de retrotransposons Copia, ambos em Arabidopsis.

Paralelamente, foram também relatadas particularidades de subgrupos específicos de retrotransposons, que auxiliaram na determinação futura de linhagens evolutivas. Entre os elementos Gypsy, observou-se que boa parte dos retrotransposons desse tipo possui um domínio chromodomain na integrase. Com relação aos retrotransposons Copia, foram descritas as Sireviruses, linhagem evolutiva de elementos exclusiva de plantas, cuja maioria dos membros têm o gene envelope em sua ORF e a proteína Gag destes elementos é capaz de interagir com outras proteínas da célula (Havecker, et al., 2005).

Ainda são escassos os trabalhos que se aprofundam na descrição das linhagens evolutivas dos retrotransposons com LTR em plantas, sobretudo em relação aos elementos Copia. Uma das razões para tal é que a maioria dos trabalhos optava por utilizar poucas seqüências, porém completas.

No entanto, recentemente começaram a surgir alguns trabalhos que tratam da diversidade evolutiva de retrotransposons utilizando-se apenas uma região conservada da ORF. Gorinsek, et al. $(2004,2005)$, a partir de uma série de dados de diversas espécies vegetais, identificou 5 linhagens evolutivas de retrotransposons Gypsy com chromodomain em plantas, baseando-se na região da transcriptase reversa destes elementos. Três das 5 linhagens correspondiam à linhagens anteriormente descritas por Marín e Lloréns (2000) em Arabidopsis thaliana. As outras 2 linhagens descritas por Gorinsek, et al. (2004, 2005) foram identificadas graças ao acúmulo de uma grande quantidade de dados genômicos. Uma delas, a linhagem CRM, é composta por retrotransposons do tipo Gypsy presentes exclusivamente em centrômeros, dessa forma comprovando que as famílias de retrotransposons descritas por Miller, et al. (1998) têm provável origem filogenética comum. O domínio chromodomain desta linhagem é claramente distinto do observado para os demais retrotransposons com chromodomain, o que provavelmente confere a especificidade de inserção desta linhagem evolutiva (Gao, 
et al., 2008). A outra linhagem, Chlamyvir, seria exclusiva de elementos provenientes da alga Chlamydomonas renhardtii.

Posteriormente, Lloréns, et al. (2008) demonstrou que utilizando-se qualquer domínio da ORF de retrotransposons e qualquer método filogenético era possível estabelecer os mesmos grandes grupos para os retrotransposons Gypsy. Em plantas, o trabalho de Lloréns, et al. (2008) encontrou 5 das 6 linhagens evolutivas descritas por Gorinsek, et al. $(2004,2005)$ - apenas um dos nomes utilizados para denominar estas linhagens foi diferente. Não foi identificada a linhagem Chlamyvir porque o estudo de Llorens, et al. (2008) não utilizou os dados genômicos da alga Chlamydomonas renhardtii.

A análise de Lloréns, et al. (2008) também estabeleceu modelos estatísticos que permitem classificar qualquer fragmento da ORF de um retrotransposon Gypsy em uma linhagem evolutiva. Com isso, pode-se dizer que em plantas (com exceção de Chlamydomonas renhardtii) foram identificadas 4 linhagens evolutivas de retrotransposons Gypsy com chromodomain: Del (por Lloréns, et al., 2008) ou Tekay (por Gorinsek et al., 2004, 2005), CRM (por ambos os trabalhos - exclusivo de centrômeros), Reina e Galadriel. Sem chromodomain, existem em plantas as linhagens Athila e Tat (Lloréns, et al., 2008).

Para os retrotransposons Copia vegetais, Wicker e Keller (2007) utilizaram dados genômicos de arroz, Arabidopsis thaliana e de plantas da família Triticaceae para a identificação de linhagens evolutivas. Baseando-se em uma árvore filogenética traçada com a transcriptase reversa, em características estruturais dos elementos completos e em seqüências consenso da região PBS e PPT, foram identificadas 6 linhagens evolutivas: Maximus, Ivana, Ale, Angela, TAR e Bianca. As características estruturais dos representantes da linhagem evolutiva Maximus permite concluir que as Sireviruses descritas por Havecker et al. (2005) fazem parte desta linhagem evolutiva.

Assim sendo, atualmente sabe-se que os retrotransposons com LTR possuem ancestralidade comum (Friesen, et al., 2001), mas é possível ir ainda mais longe dentro da categorização destes elementos. Para isso, a utilização de segmentos conservados da ORF de retrotransposons com LTR em plantas auxilia a compreensão da diversidade de linhagens evolutivas existente entre os elementos do tipo Copia e Gypsy - mesmo sabendo-se que as forças evolutivas não são idênticas entre as diferentes regiões da ORF de um retrotransposon. Para 
compreensão dessa diversidade, foi fundamental a grande disponibilidade de dados genômicos hoje acessível.

\subsection{A cana-de-açúcar como modelo para estudo de elementos transponíveis}

Como foi colocado inicialmente, a cana-de-açúcar é uma gramínea de grande importância econômica cujo genoma é bastante complexo devido à fenômenos de hibridação, poliploidia e aneuploidia.

Embora sejam conhecidos padrões transcricionais e transposicionais de TEs em espécies-modelo, pouco se sabe a respeito de aspectos genômicos e transcricionais de TEs em espécies híbridas e aneuplóides. Dessa maneira, a canade-açúcar é um modelo interessante para o estudo da distribuição genômica e padrões transcricionais de TEs em um genoma complexo.

Com a disponibilidade de um grande banco de ESTs, Rossi, et al. (2001) fez um primeiro catálogo dos elementos transponíveis expressos em cana. Foi observada uma grande diversidade de elementos expressos, dos quais destacou-se o grupo Mutator entre os transposons de DNA. Foram identificadas 4 linhagens de elementos desse grupo em cana (Rossi, et al., 2004), das quais duas delas são domesticadas (Saccaro Júnior, et al., 2007).

Araújo, et al. (2005) realizaram uma análise por macroarranjos de 68 clones de cDNA inicialmente analisados por Rossi, et al. (2001), dos quais 30 eram relacionados a retrotransposons com LTR. A Figura 6 detalha o perfil de expressão destes elementos em 4 tecidos de cana-de-açúcar: 


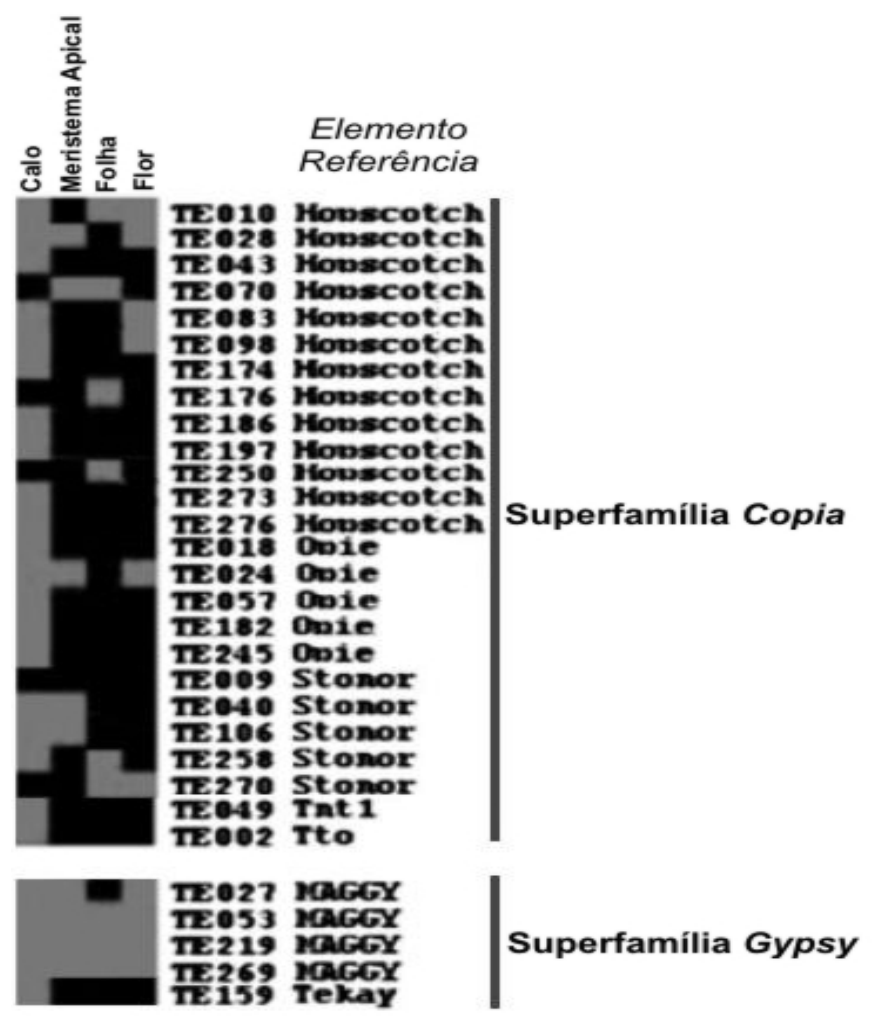

Figura 6 - Análise da expressão de retrotransposons com LTR em cana-de-açúcar. As linhas representam os clones de cDNA de cana de açúcar (TEXXX) relacionados à elementos-referência. As colunas representam os diferentes tecidos (calo, meristema apical, folhas e flores). Cinza e preto indicam presença e ausência de transcritos, respectivamente (Adaptado de Araújo, et al., 2005).

Desses 30 cDNAs relacionados a retrotransposons 25 apresentaram expressão em calo. Para o clone de cDNA TE197, relacionado ao retrotransposon Hopscotch, foi inclusive demonstrado funcionalmente que o promotor deste elemento tem atividade específica em calos de cana (Araújo, et al., 2005). Ressaltase que entre diferentes cDNAs relacionados a um mesmo elemento referência, há variações no padrão transcricional. Isso pode estar ocorrendo em função de variações entre elementos em sua região promotora (U3 da LTR) ou mesmo porque elementos de famílias distintas foram relacionados ao mesmo elemento-referência. Nesse sentido, é importante uma reclassificação dos cDNAs relacionados a retrotransposons com base em critérios filogenômicos.

Embora tenham sido mais abundantes os cDNAs relacionados ao retrotransposon Hopscotch, o cDNA mais longo dentre os elementos da superfamília Copia é o que foi relacionado ao retrotransposon Tht1 de fumo, um dos elementos mais estudados em plantas. Em razão da cobertura de seu cDNA em relação a um elemento completo sua relação inicial com um elemento de uma planta 
eudicotiledônea, este elemento selecionado para o isolamento e caracterização de uma família de retrotransposons em cana.

A partir de inferências in silico com base nos bancos de dados de ESTs, estima-se que pouco mais de $2 \%$ do transcriptoma de cana é composto de seqüências relacionadas a elementos genéticos móveis (Vettore, et al., 2003); porcentagem semelhante foi observada em trigo, outra gramínea poliplóide (Li, et al., 2004). Comparando-se estes dados aos do transcriptoma de milho (uma gramínea diplóide), que apresentou menos de 0,1\% de transcritos relacionados a TES (Meyers, et al., 2001), pode-se relacionar os eventos recentes de poliploidia e hibridação à uma ativação transcricional de elementos transponíveis em gramíneas.

A partir dos dados de seqüenciamento genômico, confirma-se que boa parte das espécies vegetais atuais passaram por algum evento de poliploidia, ou seja, duplicação completa de seu genoma, ao longo de sua história evolutiva (Paterson, et al., 2004). Estes eventos envolvem uma reorganização estrutural do genoma vegetal, que sofre assim translocações, deleções e mudanças nos padrões de metilação do DNA e da expressão gênica. Uma vez que as espécies-modelo atuais são diplóides, especula-se que boa parte delas são "paleopoliplóides" (Blanc e Wolfe, 2004). Como nas espécies atuais já não é mais possível rastrear os passos percorridos pelo genoma para atingir sua estabilidade atual, o estudo de poliplóides recentes é de grande valia para a compreensão de como o "choque genômico" atua na conformação do genoma vegetal e na distribuição de elementos transponíveis (Chen, 2007).

Nesse sentido, já foi demonstrado que em híbridos artificiais anfidiplóides (criados pela hibridização de duas espécies distintas) de trigo ocorre a ativação de retrotransposons com LTR e estes alteram a expressão de genes adjacentes (Kashkush, et al., 2003). Dessa forma, é razoável pensar que a cana-de-açúcar, planta na qual foi identificado um considerável número de transcritos relacionados à TEs quando comparada a outras espécies vegetais (Rossi, et al., 2001; Vettore, et al., 2003; Araújo, et al., 2005), tenha sua expressão gênica influenciada pela ação de elementos transponíveis.

Por fim, os recorrentes históricos de poliploidia em cana - já que as espécies que originaram a cana-de-açúcar comercial também são poliplóides - somado ao fato da recente hibridação das variedades utilizadas hoje em dia (por volta de 100 anos), leva a crer que este genoma ainda está em fase de reestruturação. Sabendo- 
se da importância dos TEs na evolução e reorganização do genoma, e o predomínio de retrotransposons com LTRs nos genomas vegetais, é de fundamental relevância a caracterização destes elementos presentes no genoma de cana. 


\section{Conclusões}

- Uma nova família de retrotransposons da superfamília Copia foi clonada a partir do genoma de cana de açúcar variedade SP80-3280. Este elemento denominado SURE (SUgarcane REtrotransposon);

- SURE é um elemento da linhagem Ivana de retrotransposons da superfamília Copia. Apresenta baixo número de cópias, baixa diversidade entre estas cópias, é transcricionalmente ativo em tecidos pouco diferenciados, apresenta polimorfismo de inserção em diferentes variedades de cana, bem como está presente espécies genitoras e espécies relacionadas;

- O genoma da cana-de-açúcar apresenta grande colinearidade com os genomas de sorgo e arroz em dois loci analisados, que apresentam inserções de SURE;

- Os cDNAs e seqüências completas de retrotransposons com LTR de canade-açúcar podem ser classificados em linhagens evolutivas ubíquas no reino vegetal;

- O conjunto de seqüências relacionado a TEs mais representado no banco de transcritos de cana-de-açúcar foi reunido como uma nova uma nova família de retrotranspons da superfamília Copia em cana-de-açúcar: Garapa;

- Garapa é um elemento largamente distribuído nos cromossomos de cana;

- SURE e Garapa apresentam-se como duas linhagens de Copia (Ivana e Ale) com padrões distintos de amplificação no genoma de cana-de-açúcar. 


\section{Referências*}

Alix K, Baurens FC, Paulet F, Glaszmann JC, D'Hont A. Isolation and characterization of a satellite DNA family in the Saccharum complex. Genome. 1998;41:854-64.

Alix K, Ryder CD, Moore J, King GJ, Pat Heslop-Harrison JS. The genomic organization of retrotransposons in Brassica oleracea. Plant Mol Biol. 2005;59:83951.

Al-Janabi, SM, Honeycutt, RJ, McClelland, M, Sobral, BWS. A genetic linkage map of Saccharum spontaneum L. 'SES 208'. Genetics. 1993;134:1249-60.

Altschul SF, Madden TL, Schäffer AA, Zhang J, Zhang Z, Miller W, Lipman DJ. Gapped BLAST and PSI-BLAST:a new generation of protein database search programs. Nucleic Acids Res. 1997;25:3389-402.

Amalraj VA, Balasundaram N. On the taxonomy of the members of 'Saccharum complex'. Genet Resour Crop Evol. 2006;53:35-41.

Ammiraju JS, Zuccolo A, Yu Y, Song X, Piegu B, Chevalier F, Walling JG, Ma J, Talag J, Brar DS, SanMiguel PJ, Jiang N, Jackson SA, Panaud O, Wing RA. Evolutionary dynamics of an ancient retrotransposon family provides insights into evolution of genome size in the genus Oryza. Plant J. 2007;52:342-51.

Araújo PG, Casacuberta JM, Costa AP, Hashimoto RY, Grandbastien MA, Van Sluys MA. Retrolyc1 subfamilies defined by different U3 LTR regulatory regions in the Lycopersicon genus. Mol Genet Genomics. 2001;266:35-41.

Araújo PG, Rossi M, de Jesus EM, Saccaro Jr NL, Kajihara D, Massa R, de Felix JM, Drummond RD, Falco MC, Chabregas SM, Ulian EC, Menossi M, Van Sluys MA. Transcriptionally active transposable elements in recent hybrid sugarcane. Plant $\mathrm{J}$. 2005;44:707-17.

Asnaghi C, Paulet F, Kaye C, Grivet L, Glaszmann JC, D'Hont A. Application of synteny across the Poaceae to determine the map location of a rust resistance gene of sugarcane. Theor Appl Genet. 2000;10:962-9.

Bachem, CWB. cDNA/AFLP - A tool for transcriptome analysis [página na Internet]. Wageningen:WUR;2004. Disponível em:http://www.plantbreeding.wur.nl/Projects/ Markers/aflp_cDNA-AFLP.html [2009 Jan 19].

\footnotetext{
* De acordo com:

International Committee of Medical Journal Editors. Uniform requirements for manuscripts submitted to Biomedical Journal: sample references. Available from: http://www.icmje.org [2007 May 22].
} 
Beguiristain T, Grandbastien MA, Puigdomènech $\mathrm{P}$, Casacuberta JM. Three Tnt1 subfamilies show different stress-associated patterns of expression in tobacco. Consequences for retrotransposon control and evolution in plants. Plant Physiol. 2001;127:212-21.

Belyayev A, Raskina O, Nevo E. Variability of the chromosomal distribution of Ty3gypsy retrotransposons in the populations of two wild Triticeae species. Cytogenet Genome Res. 2005;109:43-9.

Bennetzen JL, Ma J, Devos KM. Mechanisms of recent genome size variation in flowering plants. Ann Bot (Lond). 2005;95:127-32.

Bennetzen JL. Transposable elements, gene creation and genome rearrangement in flowering plants. Curr Opin Genet Dev. 2005;15:621-7

Bhattacharyya MK, Smith AM, Ellis TH, Hedley C, Martin C. The wrinkled-seed character of pea described by Mendel is caused by a transposon-like insertion in a gene encoding starch-branching enzyme. Cell. 1990;60:115-22.

Biémont C, Vieira C. Genetics:junk DNA as an evolutionary force. Nature. 2006;443:521-4.

Blanc G, Wolfe KH. Widespread paleopolyploidy in model plant species inferred from age distributions of duplicate genes. Plant Cell. 2004;16:1667-78.

Böhmdorfer G, Hofacker IL, Garber K, Jelenic S, Nizhynska V, Hirochika H, Stadler PF, Bachmair A. Unorthodox mRNA start site to extend the highly structured leader of retrotransposon Tto1 mRNA increases transposition rate. RNA. 2005;11:1181-91.

Bundock P, Hooykaas P. An Arabidopsis hAT-like transposase is essential for plant development. Nature. 2005;436:282-4.

Camargo SR, Cançado GM, Ulian EC, Menossi M. Identification of genes responsive to the application of ethanol on sugarcane leaves. Plant Cell Rep. 2007;26:2119-28.

Cartharius K, Frech K, Grote K, Klocke B, Haltmeier M, Klingenhoff A, Frisch M, Bayerlein M, Werner T. MatInspector and beyond:promoter analysis based on transcription factor binding sites. Bioinformatics. 2005;21:2933-42.

Casacuberta JM, Santiago N. Plant LTR-retrotransposons and MITEs:control of transposition and impact on the evolution of plant genes and genomes. Gene. 2003;311:1-11.

Chen ZJ. Genetic and epigenetic mechanisms for gene expression and phenotypic variation in plant polyploids. Annu Rev Plant Biol. 2007;58:377-406.

Childs KL, Hamilton JP, Zhu W, Ly E, Cheung F, Wu H, Rabinowicz PD, Town CD, Buell CR, Chan AP. The TIGR Plant Transcript Assemblies database. Nucleic Acids Res. 2007;35:D846-51. 
Cooperativa dos Plantadores de Cana da Zona de Guariba. Produção de cana cresce 14\% em safra alcooleira. Rev Coplana. 2008;44:5 [periódico online]. Disponível em: http://www.coplana.com/gxpfiles/ws001/ design/RevistaCoplana/ 2008/Fevereiro/pag05.pdf [2009 Jan 19].

Craig NL. Target site selection in transposition. Annu Rev Biochem. 1997;66:437-74.

Cuadrado A, Acevedo R, Moreno Díaz de la Espina S, Jouve N, de la Torre C. Genome remodelling in three modern $\mathrm{S}$. officinarum $\times$ S. spontaneum sugarcane cultivars. J Exp Bot. 2004;55:847-54.

Curcio MJ, Derbyshire KM. The outs and ins of transposition:from mu to kangaroo. Nat Rev Mol Cell Biol. 2003;4:865-77.

Da Silva, J, Sorrells, ME, Burnquist, WL, Tanksley, SD. RFLP linkage map and genome analysis of Saccharum spontaneum. Genome. 1993;36:782-91.

Dawkins, R. O Gene Egoísta. São Paulo:Itatiaia EDUSP;1976.

De Jesus EM. Estudo de dois grupos de elementos de cana-de-açúcar homológos à superfamília hAT de transposons [tese (Doutorado em Botânica)]. São Paulo (Brasil):Instituto de Biociências da Universidade de São Paulo;2007.

Dereeper A, Guignon V, Blanc G, Audic S, Buffet S, Chevenet F, Dufayard JF, Guindon S, Lefort V, Lescot M, Claverie JM, Gascuel O. Phylogeny.fr:robust phylogenetic analysis for the non-specialist. Nucleic Acids Res. 2008;36:W465-9.

Deveaux $Y$, Toffano-Nioche $C$, Claisse G, Thareau V, Morin $H$, Laufs $P$, Moreau $H$, Kreis M, Lecharny A. Genes of the most conserved WOX clade in plants affect root and flower development in Arabidopsis. BMC Evol Biol. 2008;8:291. Disponível em:http://www.biomedcentral.com/1471-2148/8/291/ [2009 Jan 19]

Devos KM, Ma J, Pontaroli AC, Pratt LH, Bennetzen JL. Analysis and mapping of randomly chosen bacterial artificial chromosome clones from hexaploid bread wheat. Proc Natl Acad Sci U S A. 2005;102:19243-8.

D'Hont A, Lu YH, León DG, Grivet L, Feldmann P, Lanaud C, Glaszmann JC. A molecular approach to unrevealing the genetics of sugarcane, a complex polyploid of the Andropogoneae tribe. Genome. 1994;37:222-30.

D'Hont A, Grivet L, Feldmann P, Rao S, Berding N, Glaszmann JC. Characterisation of the double genome structure of modern sugarcane cultivars (Saccharum spp.) by molecular cytogenetics. Mol Gen Genet. 1996;250:405-13.

D'Hont A. Unraveling the genome structure of polyploids using FISH and GISH;examples of sugarcane and banana.Cytogenet Genome Res. 2005;109:27-33. 
Diao X, Freeling M, Lisch D. Horizontal transfer of a plant transposon. PLoS Biol. 2006;4:e5.

Dillon SL, Shapter FM, Henry RJ, Cordeiro G, Izquierdo L, Lee LS. Domestication to crop improvement:genetic resources for Sorghum and Saccharum (Andropogoneae). Ann Bot (Lond). 2007;100:975-89.

Doolittle WF, Sapienza C. Selfish genes, the phenotype paradigm and genome evolution. Nature. 1980. 17;284:601-3.

Droege M, Hill B. The Genome Sequencer FLX System--longer reads, more applications, straight forward bioinformatics and more complete data sets. J Biotechnol. 2008;136:3-10.

Dufour, P, Deu, M, Grivet, L, D'Hont, A, Paulet, F, Bouet, A, Lanaud, C, Glaszmann, JC, Hamon, P. Construction of a composite sorghum genome map and comparison with sugarcane, a related complex polyploid. Theor Appl Genet. 1997;94:409-18.

Echenique V, Stamova B, Wolters P, Lazo G, Carollo L, Dubcovsky J. Frequencies of Ty1- copia and Ty3- gypsy retroelements within the Triticeae EST databases. Theor Appl Genet. 2002;104:840-844.

Edgar RC. MUSCLE:a multiple sequence alignment method with reduced time and space complexity. BMC Bioinformatics. 2004;5:113. Disponível em:http://www.biomedcentral.com/1471-2105/5/113 [2009 Jan 19].

Ewing B, Green P. Base-calling of automated sequencer traces using phred. II. Error probabilities. Genome Res. 1998;8:186-94.

Ewing B, Hillier L, Wendl MC, Green P. Base-calling of automated sequencer traces using phred. I. Accuracy assessment. Genome Res. 1998;8:175-85.

Felsenstein J. Evolutionary trees from DNA sequences:a maximum likelihood approach. J Mol Evol. 1981;17:368-76.

Feschotte C, Jiang N, Wessler SR. Plant transposable elements:where genetics meets genomics. Nat Rev Genet. 2002;3:329-41.

Feschotte C. Transposable elements and the evolution of regulatory networks. Nat Rev Genet. 2008;9:397-405.

Finnegan, DJ Eukaryotic transposable elements and genome evolution. Trends Genet. 1989;5:103-7.

Flavell AJ, Knox MR, Pearce SR, Ellis TH. Retrotransposon-based insertion polymorphisms (RBIP) for high throughput marker analysis. Plant J. 1998;16:643-50.

Frech K, Brack-Werner R, Werner T. Common modular structure of lentivirus LTRs. Virology. 1996;224:256-67. 
Friesen N, Brandes A, Heslop-Harrison JS. Diversity, origin, and distribution of retrotransposons (gypsy and copia) in conifers. Mol Biol Evol. 2001;18:1176-88.

Fukai E, Dobrowolska AD, Madsen LH, Madsen EB, Umehara Y, Kouchi H, Hirochika $\mathrm{H}$, Stougaard J. Transposition of a 600 thousand-year-old LTR retrotransposon in the model legume Lotus japonicus. Plant Mol Biol. 2008;68:653-63.

Gao X, Havecker ER, Baranov PV, Atkins JF, Voytas DF. Translational recoding signals between gag and pol in diverse LTR retrotransposons.RNA. 2003;9:1422-30.

Gao X, Hou Y, Ebina H, Levin HL, Voytas DF. Chromodomains direct integration of retrotransposons to heterochromatin. Genome Res. 2008;18:359-69.

Garcia AAF. Cenário atual do mapeamento genético da cana-de-açúcar [página na internet]. Cordeirópolis:IAC. Disponível em:http:// www.apta.sp.gov.br/cana/Anexos/PPaper_sessao_5_Augusto.pdf. [2009 Jan 19].

Genetics and Molecular Biology. Ribeirão Preto, SP: Sociedade Brasileira de Genética; 24;2001.

Gordon D, Abajian C, Green P. Consed:a graphical tool for sequence finishing. Genome Res. 1998;8:195-202.

Gorinsek B, Gubensek F, Kordis D. Evolutionary genomics of chromoviruses in eukaryotes. Mol Biol Evol. 2004;21:781-98.

Gorinsek B, Gubensek F, Kordis D. Phylogenomic analysis of chromoviruses. Cytogenet Genome Res. 2005;110:543-52.

Grandbastien MA, Audeon C, Bonnivard E, Casacuberta JM, Chalhoub B, Costa AP, Le QH, Melayah D, Petit M, Poncet C, Tam SM, Van Sluys MA, Mhiri C. Stress activation and genomic impact of Tnt1 retrotransposons in Solanaceae. Cytogenet Genome Res. 2005;110:229-41.

Grandbastien MA, Spielmann A, Caboche M. Tnt1, a mobile retroviral-like transposable element of tobacco isolated by plant cell genetics. Nature. 1989;337:376-80.

Griffths, AJF, Gelbart, WM, Miller, JH, Lewontin, RC. (2001). Genética Moderna. Trad. L.O.M. Barbosa e P.A. Motta. Guanabara Koogan:Rio de Janeiro;2001. 589p.

Grivet L, Arruda P. Sugarcane genomics:depicting the complex genome of an important tropical crop. Curr Opin Plant Biol. 2002;5:122-7.

Grivet L, D'Hont A, Roques D, Feldmann P, Lanaud C, Glaszmann JC. RFLP mapping in cultivated sugarcane (Saccharum spp.):genome organization in a highly polyploid and aneuploid interspecific hybrid. Genetics. 1996;142:987-1000.

Grivet, L, Daniels C, Glaszmann JC, D'Hont A. A review of recent molecular genetics evidence for sugarcane evolution and domestication. Ethnobot Res Appl. 2004;2:917. 
Guimarães, CT, Sills, GR, Sobral, BWS. Comparative mapping of Andropogoneae:Saccharum L. (sugarcane) and its relation to sorghum and maize. Proc Natl Acad Sci USA. 1997;94:14261-6.

Guindon S, Gascuel O. A simple, fast, and accurate algorithm to estimate large phylogenies by maximum likelihood. Syst Biol. 2003;52:696-704.

Guindon S, Lethiec F, Duroux P, Gascuel O. PHYML Online--a web server for fast maximum likelihood-based phylogenetic inference. Nucleic Acids Res. 2005;33:W557-9.

Hanahan, D. Studies on transformation of Escherichia coli with plasmids. J. Mol. Biol. 1983;136:557-80.

Haren L, Ton-Hoang B, Chandler M. Integrating DNA:transposases and retroviral integrases. Annu Rev Microbiol. 1999;53:245-8.

Hasegawa M, Kishino $\mathrm{H}$, Yano $\mathrm{T}$. Dating of the human-ape splitting by a molecular clock of mitochondrial DNA. J Mol Evol. 1985;22(2):160-74.

Havecker ER, Gao X, Voytas DF. The diversity of LTR retrotransposons. Genome Biol. 2004;5:225. Disponível em:http://genomebiology.com/2004/5/6/225 [2009 Jan 20].

Havecker ER, Gao X, Voytas DF. The Sireviruses, a plant-specific lineage of the Copia retrotransposons, interact with a family of proteins related to dynein light chain 8. Plant Physiol. 2005;139:857-68.

Hawkins JS, Kim H, Nason JD, Wing RA, Wendel JF. Differential lineage-specific amplification of transposable elements is responsible for genome size variation in Gossypium. Genome Res. 2006;16:1252-61.

Heslop-Harrison JS, Brandes A, Taketa S, Schmidt T, Vershinin AV, Alkhimova EG, Kamm A, Doudrick RL, Schwarzacher T, Katsiotis A, Kubis S, Kumar A, Pearce SR, Flavell AJ, Harrison GE. The chromosomal distributions of Ty1-copia group retrotransposable elements in higher plants and their implications for genome evolution. Genetica. 1997;100:197-204.

Hess JL, Bittner CB, Zeisig DT, Bach C, Fuchs U, Borkhardt A, Frampton J, Slany RK. C-Myb is an essential downstream target for homeobox-mediated transformation of hematopoietic cells. Blood. 2006 Jul 1;108(1):297-304.

Hirochika H, Sugimoto K, Otsuki Y, Tsugawa H, Kanda M. Retrotransposons of rice involved in mutations induced by tissue culture. Proc Natl Acad Sci U S A. 1996;93:7783-8. 
Hoarau JY, Grivet L, Offmann B, Raboin LM, Diorflar JP, Payet J, Hellmann M, D'Hont A, Glaszmann JC. Genetic dissection of a modern sugarcane cultivar (Saccharum spp.).II. Detection of QTLs for yield components. Theor Appl Genet. 2002;105:1027-37.

Hodkinson TR, Chase MW, Lldeó MD, Salamin N, Renvoize A. Phylogenetics of Miscanthus, Saccharum and related genera (Saccharinae, Andropogoneae, Poaceae) based on DNA sequences from ITS nuclear ribosomal DNA and plastid trnL intron and trnL-F intergenic spacers. J Plant Res. 2002;115:381-92.

Hudson ME, Lisch DR, Quail PH. The FHY3 and FAR1 genes encode transposaserelated proteins involved in regulation of gene expression by the phytochrome Asignaling pathway. Plant J. 2003;34:453-71.

Irvine JE. Saccharum species as horticultural classes. Theor Appl Genet. 1999;98:186-94.

Jannoo N, Grivet L, Chantret N, Garsmeur O, Glaszmann JC, Arruda P, D'Hont A. Orthologous comparison in a gene-rich region among grasses reveals stability in the sugarcane polyploid genome. Plant J. 2007;50:574-85.

Jiang N, Jordan IK, Wessler SR. Dasheng and RIRE2. A nonautonomous long terminal repeat element and its putative autonomous partner in the rice genome. Plant Physiol. 2002;130:1697-705.

Jiao $\mathrm{Y}$, Deng XW. A genome-wide transcriptional activity survey of rice transposable element-related genes. Genome Biol. 2007;8:R28. Disponível em:http://genomebiology.com/2007/8/2/R28 [2009 Jan 20].

Jin $\mathrm{H}$, Martin $\mathrm{C}$. Multifunctionality and diversity within the plant MYB-gene family. Plant Mol Biol. 1999;41:577-85.

Jordan, E, Saedler, H, Starlinger, P. Strong-polar mutations in the transferase gene of the galactose operon in E.coli. Mol Gen Genet. 1967;100:296-306.

Jukes TH, Cantor CR. Evolution of protein molecules. In:Munro HN, editor. Mammalian protein metabolism. New York:Academic Press;1969, p. 21-123.

Kalendar R, Vicient CM, Peleg O, Anamthawat-Jonsson K, Bolshoy A, Schulman AH. Large retrotransposon derivatives:abundant, conserved but nonautonomous retroelements of barley and related genomes. Genetics. 2004;166:1437-50.

Kapitonov VV, Jurka J. A universal classification of eukaryotic transposable elements implemented in Re pbase. Nat Rev Genet. 2008;9:411-2.

Kashkush K, Feldman M, Levy AA. Transcriptional activation of retrotransposons alters the expression of adjacent genes in wheat. Nat Genet. 2003;33:102-6.

Kumar A, Bennetzen JL. Plant retrotransposons. Annu Rev Genet. 1999;33:479-532. 
Kwiatkowska D. Flowering and apical meristem growth dynamics. J Exp Bot. 2008;59:187-201.

Larkin MA, Blackshields G, Brown NP, Chenna R, McGettigan PA, McWilliam H, Valentin F, Wallace IM, Wilm A, Lopez R, Thompson JD, Gibson TJ, Higgins DG. Clustal W and Clustal X version 2.0. Bioinformatics. 2007;23:2947-8.

Laten HM, Majumdar A, Gaucher EA. SIRE-1, a copia/Ty1-like retroelement from soybean, encodes a retroviral envelope-like protein. Proc Natl Acad Sci U S A. 1998;95:6897-902.

Liang C, Jaiswal P, Hebbard C, Avraham S, Buckler ES, Casstevens T, Hurwitz B, McCouch S, Ni J, Pujar A, Ravenscroft D, Ren L, Spooner W, Tecle I, Thomason J, Tung CW, Wei X, Yap I, Youens-Clark K, Ware D, Stein L. Gramene:a growing plant comparative genomics resource. Nucleic Acids Res. 2008;36:D947-53.

Lima, MLA, Garcia, AAF, Oliveira, KM, Matsuoka, S., Arizono H, de Souza, Jr., CL, de Souza, AP. Analysis of genetic similarity detected by AFLP and coefficient of parentage among genotypes of sugarcane (Saccharum spp). Theor Appl Genet. 2002;104:30-8.

Lin R, Ding L, Casola C, Ripoll DR, Feschotte C, Wang H. Transposase-derived transcription factors regulate light signaling in Arabidopsis. Science. 2007;318:13025. Erratum in:Science. 2007;318:1866.

Lloréns C, Futami R, Bezemer D, Moya A. The Gypsy Database (GyDB) of mobile genetic elements. Nucleic Acids Res. 2008;36:D38-46.

Lopes FR, Carazzolle MF, Pereira GA, Colombo CA, Carareto CM. Transposable elements in Coffea (Gentianales:Rubiacea) transcripts and their role in the origin of protein diversity in flowering plants. Mol Genet Genomics. 2008;279:385-401.

Ma J, Bennetzen JL. Rapid recent growth and divergence of rice nuclear genomes. Proc Natl Acad Sci U S A. 2004;101:12404-10.

Madsen LH, Fukai E, Radutoiu S, Yost CK, Sandal N, Schauser L, Stougaard J. LORE1, an active low-copy-number TY3-gypsy retrotransposon family in the model legume Lotus japonicus. Plant J. 2005;44:372-81.

Malik HS, Eickbush TH. Phylogenetic analysis of ribonuclease $\mathrm{H}$ domains suggests a late, chimeric origin of LTR retrotransposable elements and retroviruses. Genome Res. 2001;11:1187-97.

Manetti ME, Rossi M, Costa AP, Clausen AM, Van Sluys MA. Radiation of the Tnt1 retrotransposon superfamily in three Solanaceae genera. BMC Evol Biol. 2007;7:34. Disponível em:http://www.biomedcentral.com/1471-2148/7/34/ [2009 Jan 29] 
Marchler-Bauer A, Anderson JB, Derbyshire MK, DeWeese-Scott C, Gonzales NR, Gwadz M, Hao L, He S, Hurwitz DI, Jackson JD, Ke Z, Krylov D, Lanczycki CJ, Liebert CA, Liu C, Lu F, Lu S, Marchler GH, Mullokandov M, Song JS, Thanki N, Yamashita RA, Yin JJ, Zhang D, Bryant SH. CDD:a conserved domain database for interactive domain family analysis. Nucleic Acids Res. 2007;35:D237-40.

Margulies M, Egholm M, Altman WE, Attiya S, Bader JS, Bemben LA, Berka J, Braverman MS, Chen YJ, Chen Z, Dewell SB, Du L, Fierro JM, Gomes XV, Godwin BC, He W, Helgesen S, Ho CH, Irzyk GP, Jando SC, Alenquer ML, Jarvie TP, Jirage KB, Kim JB, Knight JR, Lanza JR, Leamon JH, Lefkowitz SM, Lei M, Li J, Lohman KL, Lu H, Makhijani VB, McDade KE, McKenna MP, Myers EW, Nickerson E, Nobile JR, Plant R, Puc BP, Ronan MT, Roth GT, Sarkis GJ, Simons JF, Simpson JW, Srinivasan M, Tartaro KR, Tomasz A, Vogt KA, Volkmer GA, Wang SH, Wang Y, Weiner MP, Yu P, Begley RF, Rothberg JM. Genome sequencing in microfabricated high-density picolitre reactors. Nature. 2005;437:376-80. Erratum in:Nature. 2006;441:120.

Marín I, Lloréns C. Gypsy retrotransposons:description of new Arabidopsis thaliana elements and evolutionary perspectives derived from comparative genomic data. Mol Biol Evol. 2000;17:1040-9.

Martienssen RA, Colot V. DNA methylation and epigenetic inheritance in plants and filamentous fungi. Science. 2001;293:1070-4.Erratum in:Science 2001;293:1997.

Martínez-Izquierdo JA, García-Martínez J, Vicient CM. What makes Grande1 retrotransposon different? Genetica. 1997;100:15-28.

Matsuoka Y, Tsunewaki K. Evolutionary dynamics of Ty1-copia group retrotransposons in grass shown by reverse transcriptase domain analysis. Mol Biol Evol. 1999;16:208-17.

McCarthy EM, Liu J, Lizhi G, McDonald JF. Long terminal repeat retrotransposons of Oryza sativa. Genome Biol. 2002;3:RESEARCH0053.

McCarthy EM, McDonald JF. LTR_STRUC:a novel search and identification program for LTR retrotransposons. Bioinformatics. 2003;19:362-7.

McClintock $B$. The origin and behavior of mutable loci in maize. Proc Natl Acad Sci U S A. 1950;36:344-55.

Menossi M, Silva-Filho MC, Vincentz M, Van Sluys MA, Souza GM. Sugarcane functional genomics:gene discovery for agronomic trait development. Int J Plant Genomics. 2008;2008:458732.

Meyers BC, Tingey SV, Morgante M. Abundance, distribution, and transcriptional activity of repetitive elements in the maize genome. Genome Res. 2001;11:1660-76.

Miller JT, Dong F, Jackson SA, Song J, Jiang J. Retrotransposon-related DNA sequences in the centromeres of grass chromosomes. Genetics. 1998;150:1615-23. 
Ming R, Liu SC, Lin YR, da Silva J, Wilson W, Braga D, van Deynze A, Wenslaff TF, Wu KK, Moore PH, Burnquist W, Sorrells ME, Irvine JE, Paterson AH. Detailed alignment of Saccharum and sorghum chromosomes:comparative organization of closely related diploid and polyploid genomes. Genetics. 1998;150:1663-82.

Ming R, Liu SC, Moore PH, Irvine JE, Paterson AH. QTL analysis in a complex autopolyploid:genetic control of sugar content in sugarcane. Genome Res. 2001;11:2075-84.

Ming R, Wang W, Draye X, Moore H, Irvine E, Paterson AH. Molecular dissection of complex traits in autopolyploids:mapping QTLs affecting sugar yield and related traits in sugarcane. Theor Appl Genet. 2002;105:332-45.

Moreira, B. Carro flex representou 87,2\% do total vendido em 2008 [página na internet]. São Paulo:Estadao.com.br;2009. Disponível em:http://www.estadao.com.br/economia/not_eco304266,0.htm. [2009 Jan 19].

Mudge, J, Anderson, WR, Kehrer, RL, Fairbanks, DJ. A RAPD genetic map of Saccharum officinarum. Crop Sci. 1996;36:1362-6.

Murashige T, Skoog F. A revised medium for rapid growth and bioassays with tobacco tissue cultures. Physiol Plant. 1962;15:473-97.

Nair NV, Nair S, Sreenivasan TV, Mohan M. Analysis of genetic diversity and phylogeny in Saccharum and related genera using RAPD markers. Genet Resour Crop Evol. 1999;46:73-79.

Nardmann J, Werr W. The shoot stem cell niche in angiosperms:expression patterns of WUS orthologues in rice and maize imply major modifications in the course of mono- and dicot evolution. Mol Biol Evol. 2006;23:2492-504.

Neumann $\mathrm{P}$, Yan $\mathrm{H}$, Jiang $\mathrm{J}$. The centromeric retrotransposons of rice are transcribed and differentially processed by RNA interference. Genetics. 2007;176:749-61.

Nishikawa T, Vaughan DA, Kadowaki K. Phylogenetic analysis of Oryza species, based on simple sequence repeats and their flanking nucleotide sequences from the mitochondrial and chloroplast genomes. Theor Appl Genet. 2005;110:696-705.

Nogueira FTS, Schlogl PS, Camargo SR, Fernandez JH, De Rosa Jr VE, Pompermayer P, Arruda P. SsNAC23, a member of the NAC domain protein family, is associated with cold, herbivory and water stress in sugarcane. Plant Sci. 2005;169:93-106.

Notredame C, Higgins DG, Heringa J. T-Coffee:A novel method for fast and accurate multiple sequence alignment. J Mol Biol. 2000;302:205-17.

Pardue ML, Rashkova S, Casacuberta E, DeBaryshe PG, George JA, Traverse KL. Two retrotransposons maintain telomeres in Drosophila. Chromosome Res. 2005;13:443-53. 
Paterson AH, Bowers JE, Bruggmann R, Dubchak I, Grimwood J, Gundlach H, Haberer G, Hellsten U, Mitros T, Poliakov A, Schmutz J, Spannagl M, Tang H, Wang X, Wicker T, Bharti AK, Chapman J, Feltus FA, Gowik U, Grigoriev IV, Lyons E, Maher CA, Martis M, Narechania A, Otillar RP, Penning BW, Salamov AA, Wang Y, Zhang L, Carpita NC, Freeling M, Gingle AR, Hash CT, Keller B, Klein P, Kresovich S, McCann MC, Ming R, Peterson DG, Mehboob-ur-Rahman, Ware D, Westhoff P, Mayer KF, Messing J, Rokhsar DS. The Sorghum bicolor genome and the diversification of grasses. Nature. 2009;457:551-6.

Paterson $\mathrm{AH}$, Bowers JE, Chapman BA. Ancient polyploidization predating divergence of the cereals, and its consequences for comparative genomics. Proc Natl Acad Sci U S A. 2004;101:9903-8.

Paux E, Roger D, Badaeva E, Gay G, Bernard M, Sourdille P, Feuillet C. Characterizing the composition and evolution of homoeologous genomes in hexaploid wheat through BAC-end sequencing on chromosome $3 \mathrm{~B}$. Plant $\mathrm{J}$. 2006;48:463-74.

Pearce SR, Pich U, Harrison G, Flavell AJ, Heslop-Harrison JS, Schubert I, Kumar A. The Ty1-copia group retrotransposons of Allium cepa are distributed throughout the chromosomes but are enriched in the terminal heterochromatin. Chromosome Res. 1996;4:357-64.

Pearl LH, Taylor WR. A structural model for the retroviral proteases. Nature. 1987;329:351-4.

Pelsy F, Merdinoglu D. Complete sequence of Tvv1, a family of Ty 1 copia-like retrotransposons of Vitis vinifera L., reconstituted by chromosome walking. Theor Appl Genet. 2002;105:614-621.

Pereira V. Insertion bias and purifying selection of retrotransposons in the Arabidopsis thaliana genome. Genome Biol. 2004;5:R79. Disponível em:http://genomebiology.com/2004/5/10/R79 [2009 Jan 20].

Peterson-Burch BD, Voytas DF. Genes of the Pseudoviridae (Copia retrotransposons). Mol Biol Evol. 2002;19:1832-45.

Piegu B, Guyot R, Picault N, Roulin A, Saniyal A, Kim H, Collura K, Brar DS, Jackson $S$, Wing RA, Panaud O. Doubling genome size without polyploidization:dynamics of retrotransposition-driven genomic expansions in Oryza australiensis, a wild relative of rice. Genome Res. 2006;16:1262-9.

Piriyapongsa J, Jordan IK. Dual coding of siRNAs and miRNAs by plant transposable elements. RNA. 2008;14:814-21.

Qu L, Hancock JF. Detecting and mapping repulsion-phase linkage in polyploids with polysomic inheritance. Theor Appl Genet. 2001;103:136-43. 
Quandt K, Frech K, Karas H, Wingender E, Werner T. MatInd and MatInspector:new fast and versatile tools for detection of consensus matches in nucleotide sequence data. Nucleic Acids Res. 1995;23:4878-84.

Rabinowicz PD, Palmer LE, May BP, Hemann MT, Lowe SW, McCombie WR, Martienssen RA. Genes and transposons are differentially methylated in plants, but not in mammals. Genome Res. 2003;13:2658-64.

Ramallo E, Kalendar R, Schulman AH, Martínez-Izquierdo JA. Reme1, a Copia retrotransposon in melon, is transcriptionally induced by UV light. Plant Mol Biol. 2008;66:137-50.

Rico-Cabanas L, Martínez-Izquierdo JA. CIRE1, a novel transcriptionally active Ty1copia retrotransposon from Citrus sinensis. Mol Genet Genomics. 2007;277:365-77.

Rodrigues JD. Fisiologia da cana-de-açúcar [apostila na Internet]. Botucatu:Instituto de Biociências, Universidade Estadual Paulista;1995. Disponível em: http://www.residenciaagronomica.ufpr.br/bibliografia/MATURAD.pdf [2009 jan 19].

Rossi M, Araujo PG, de Jesus EM, Varani AM, Van Sluys MA. Comparative analysis of Mutator-like transposases in sugarcane. Mol Genet Genomics. 2004;272:194-203.

Rossi M, Araújo PG, Van Sluys MA. Survey of transposable elements in sugarcane expressed sequence tags (ESTs). Gen Mol Biol. 2001;24:147-154.

Sabot F, Schulman AH. Parasitism and the retrotransposon life cycle in plants:a hitchhiker's guide to the genome. Heredity. 2006;97:381-8.

Saccaro Jr NL, Van Sluys MA, de Mello Varani A, Rossi M. MudrA-like sequences from rice and sugarcane cluster as two bona fide transposon clades and two domesticated transposases. Gene. 2007;392:117-25.

Sambrook J, Fritsch EF, Maniatis T. Molecular cloning:a laboratory manual. 2nd. ed. New York: Cold Spring Harbor Laboratory;1989.

Sanger F, Nicklen S, Coulson, AR. DNA sequencing with chain-terminating inhibitors. Proc Natl Acad Sci U S A. 1977;74:5463-7.

SanMiguel P, Gaut BS, Tikhonov A, Nakajima Y, Bennetzen JL. The paleontology of intergene retrotransposons of maize. Nat Genet. 1998;20:43-5.

SanMiguel P, Tikhonov A, Jin YK, Motchoulskaia N, Zakharov D, Melake-Berhan A, Springer PS, Edwards $\mathrm{KJ}$, Lee $M$, Avramova $Z$, Bennetzen JL. Nested retrotransposons in the intergenic regions of the maize genome. Science. 1996;274:765-8.

Schlögl PS, Nogueira FT, Drummond R, Felix JM, De Rosa VE Jr, Vicentini R, Leite A, Ulian EC, Menossi M. Identification of new ABA- and MEJA-activated sugarcane bZIP genes by data mining in the SUCEST database. Plant Cell Rep. 2008;27:33545. 
Schulman AH, Flavell AJ, Ellis TH. The application of LTR retrotransposons as molecular markers in plants. Methods Mol Biol. 2004;260:145-73.

Schulman $\mathrm{AH}$. Molecular markers to assess genetic diversity. Euphytica. 2007;158:313-321.

Scortecci KC, Lima AF, Carvalho FM, Silva UB, Agnez-Lima LF, Batistuzzo de Medeiros SR. A characterization of a MutM/Fpg ortholog in sugarcane - A monocot plant. Biochem Biophys Res Commun. 2007;361:1054-60.

Silvarolla MB, Aguiar-Perecin MLR. Evaluation of chromosome number stability in two sugarcane varieties. Rev Bras Genet. 1994;17:237-42.

Smýkal P. Development of an efficient retrotransposon-based fingerprinting method for rapid pea variety identification. J Appl Genet. 2006;47:221-30.

Soares-Costa A, Beltramini LM, Thiemann OH, Henrique-Silva F. A sugarcane cystatin:recombinant expression, purification, and antifungal activity. Biochem Biophys Res Commun. 2002;296:1194-9.

Song $\mathrm{R}$, Llaca $\mathrm{V}$, Messing J. Mosaic organization of orthologous sequences in grass genomes. Genome Res. 2002;12:1549-55.

Stewart CN, Via LE. A rapid CTAB DNA isolation technique useful for RAPD fingerprinting and other PCR applications. BioTechniques.1993;14:748-51.

Stuart-Rogers C, Flavell AJ. The evolution of Ty1-copia group retrotransposons in gymnosperms. Mol Biol Evol. 2001;18:155-63.

Sugimoto K, Takeda S, Hirochika H. MYB-related transcription factor NtMYB2 induced by wounding and elicitors is a regulator of the tobacco retrotransposon Tto1 and defense-related genes. Plant Cell. 2000;12:2511-28.

Suoniemi A, Anamthawat-Jónsson K, Arna T, Schulman AH. Retrotransposon BARE1 is a major, dispersed component of the barley (Hordeum vulgare L.) genome. Plant Mol Biol. 1996;30:1321-9.

Suoniemi A, Tanskanen J, Schulman AH. Gypsy-like retrotransposons are widespread in the plant kingdom. Plant J. 1998;13(5):699-705.

Tahara M, Aoki T, Suzuka S, Yamashita H, Tanaka M, Matsunaga S, Kokumai S. Isolation of an active element from a high-copy-number family of retrotransposons in the sweetpotato genome. Mol Genet Genomics. 2004;272:116-27.

Tamura K, Dudley J, Nei M, Kumar S. MEGA4:Molecular Evolutionary Genetics Analysis (MEGA) software version 4.0. Mol Biol Evol. 2007;24:1596-9. 
Tatusova TA, Madden TL. BLAST 2 Sequences, a new tool for comparing protein and nucleotide sequences. FEMS Microbiol Lett. 1999;174:247-50. Erratum in:FEMS Microbiol Lett 1999;177:187-8.

Terol J, Castillo MC, Bargues M, Pérez-Alonso M, de Frutos R. Structural and evolutionary analysis of the copia-like elements in the Arabidopsis thaliana genome. Mol Biol Evol. 2001;18:882-92.

Tomkins JP, Yu Y, Miller-Smith H, Frisch DA, Woo SS, Wing RA. A bacterial artificial chromosome library for sugarcane. Theor Appl Genet. 1999;99:419-24.

Torquato SA. Cana-de-açúcar para indústria:o quanto vai precisar crescer. AIA [periódico online]. 2006;1:10. Disponível em: http://www.iea.sp.gov.br/out/verTexto.php?codTexto=7448. [2009 Jan 19].

Untergasser A, Nijveen H, Rao X, Bisseling T, Geurts R, Leunissen JA. Primer3Plus, an enhanced web interface to Primer3. Nucleic Acids Res. 2007;35:W71-4.

Vastenhouw NL, Plasterk RH. RNAi protects the Caenorhabditis elegans germline against transposition. Trends Genet. 2004;20:314-9. Erratum in:Trends Genet. 2005;21:36.

Velasco R, Zharkikh A, Troggio M, Cartwright DA, Cestaro A, Pruss D, Pindo M, Fitzgerald LM, Vezzulli S, Reid J, Malacarne G, lliev D, Coppola G, Wardell B, Micheletti D, Macalma T, Facci M, Mitchell JT, Perazzolli M, Eldredge G, Gatto P, Oyzerski R, Moretto M, Gutin N, Stefanini M, Chen Y, Segala C, Davenport C, Demattè L, Mraz A, Battilana J, Stormo K, Costa F, Tao Q, Si-Ammour A, Harkins T, Lackey A, Perbost C, Taillon B, Stella A, Solovyev V, Fawcett JA, Sterck L, Vandepoele K, Grando SM, Toppo S, Moser C, Lanchbury J, Bogden R, Skolnick M, Sgaramella V, Bhatnagar SK, Fontana P, Gutin A, Van de Peer Y, Salamini F, Viola R. A high quality draft consensus sequence of the genome of a heterozygous grapevine variety. PLoS ONE. 2007;2:e1326.

Vernhettes S, Grandbastien MA, Casacuberta JM. In vivo characterization of transcriptional regulatory sequences involved in the defence-associated expression of the tobacco retrotransposon Tnt1. Plant Mol Biol. 1997;35:673-9.

Vettore, AL, da Silva, FR, Kemper, EL, Arruda, P. The libraries that made SUCEST. Genet Mol Biol. 2001;24:1-7. 
Vettore AL, da Silva FR, Kemper EL, Souza GM, da Silva AM, Ferro MI, HenriqueSilva F, Giglioti EA, Lemos MV, Coutinho LL, Nobrega MP, Carrer H, França SC, Bacci Júnior M, Goldman MH, Gomes SL, Nunes LR, Camargo LE, Siqueira WJ, Van Sluys MA, Thiemann OH, Kuramae EE, Santelli RV, Marino CL, Targon ML, Ferro JA, Silveira HC, Marini DC, Lemos EG, Monteiro-Vitorello CB, Tambor JH, Carraro DM, Roberto PG, Martins VG, Goldman GH, de Oliveira RC, Truffi D, Colombo CA, Rossi M, de Araujo PG, Sculaccio SA, Angella A, Lima MM, de Rosa Júnior VE, Siviero F, Coscrato VE, Machado MA, Grivet L, Di Mauro SM, Nobrega FG, Menck CF, Braga MD, Telles GP, Cara FA, Pedrosa G, Meidanis J, Arruda P. Analysis and functional annotation of an expressed sequence tag collection for tropical crop sugarcane. Genome Res. 2003;13:2725-35.

Vicient CM, Kalendar R, Schulman AH. Envelope-class retrovirus-like elements are widespread, transcribed and spliced, and insertionally polymorphic in plants. Genome Res. 2001a;11:2041-9.

Vicient $\mathrm{CM}$, Jääskeläinen $\mathrm{MJ}$, Kalendar $\mathrm{R}$, Schulman $\mathrm{AH}$. Active retrotransposons are a common feature of grass genomes. Plant Physiol. 2001b;125:1283-92.

Vincentz M, Cara FA, Okura VK, da Silva FR, Pedrosa GL, Hemerly AS, Capella AN, Marins M, Ferreira PC, França SC, Grivet L, Vettore AL, Kemper EL, Burnquist WL, Targon ML, Siqueira WJ, Kuramae EE, Marino CL, Camargo LE, Carrer H, Coutinho LL, Furlan LR, Lemos MV, Nunes LR, Gomes SL, Santelli RV, Goldman MH, Bacci M Jr, Giglioti EA, Thiemann OH, Silva FH, Van Sluys MA, Nobrega FG, Arruda P, Menck CF. Evaluation of monocot and eudicot divergence using the sugarcane transcriptome. Plant Physiol. 2004;134:951-9.

Vitte C, Panaud O, Quesneville H. LTR retrotransposons in rice (Oryza sativa, L.):recent burst amplifications followed by rapid DNA loss. BMC Genomics. 2007;8:218. Disponível em:http://www.biomedcentral.com/1471-2164/8/218 [2009 Jan 19]

Vitte C, Panaud O. LTR retrotransposons and flowering plant genome size:emergence of the increase/decrease model. Cytogenet Genome Res. 2005;110:91-107.

Voytas DF, Cummings MP, Koniczny A, Ausubel FM, Rodermel SR. copia-like retrotransposons are ubiquitous among plants. Proc Natl Acad Sci U $S$ A. 1992;89:7124-8.

Wicker T, Keller B. Genome-wide comparative analysis of copia retrotransposons in Triticeae, rice, and Arabidopsis reveals conserved ancient evolutionary lineages and distinct dynamics of individual copia families. Genome Res. 2007;17:1072-81.

Wicker T, Sabot F, Hua-Van A, Bennetzen JL, Capy P, Chalhoub B, Flavell A, Leroy $P$, Morgante $M$, Panaud $O$, Paux E, SanMiguel $P$, Schulman AH. A unified classification system for eukaryotic transposable elements. Nat Rev Genet. 2007;8:973-82. 
Witte CP, Le QH, Bureau T, Kumar A. Terminal-repeat retrotransposons in miniature (TRIM) are involved in restructuring plant genomes. Proc Natl Acad Sci U S A. 2001;98:13778-83.

Wolfe KH, Gouy M, Yang YW, Sharp PM, Li WH. Date of the monocot-dicot divergence estimated from chloroplast DNA sequence data. Proc Natl Acad Sci U S A. 1989;86:6201-5.

Wright DA, Voytas DF. Potential retroviruses in plants:Tat1 is related to a group of Arabidopsis thaliana Gypsy retrotransposons that encode envelope-like proteins. Genetics. 1998;149:703-15.

Wu KK, Burnquist W, Sorrells ME, Tew TL, Moore PH, Tanksley SD. The detection and estimation of linkage in polyploids using single-dose restriction fragments. Theor Appl Genet. 1992;83:294-300.

Wu M, Li L, Sun Z. Transposable element fragments in protein-coding regions and their contributions to human functional proteins.Gene. 2007;401:165-71.

Xiong $\mathrm{Y}$, Eickbush $\mathrm{TH}$. Origin and evolution of retroelements based upon their reverse transcriptase sequences. EMBO J. 1990;9:3353-62.

Xiong Y, Eickbush TH. Similarity of reverse transcriptase-like sequences of viruses, transposable elements, and mitochondrial introns. Mol Biol Evol. 1988;5:675-90.

Yuan Q, Ouyang S, Wang A, Zhu W, Maiti R, Lin H, Hamilton J, Haas B, Sultana R, Cheung $\mathrm{F}$, Wortman J, Buell $\mathrm{CR}$. The institute for genomic research Osa1 rice genome annotation database. Plant Physiol. 2005;138:18-26.

Zerillo MM. Análise genômica macro comparativa entre Leifsonia xyli subsp. cynodontis e Leifsonia xyli subsp. xyli [tese (Doutorado em Biotecnologia)]. São Paulo (Brasil): Instituto de Ciências Biomédicas da Universidade de São Paulo; 2008.

Zhang P, Li W, Fellers J, Friebe B, Gill BS. BAC-FISH in wheat identifies chromosome landmarks consisting of different types of transposable elements. Chromosoma. 2004;112:288-99.

Zhou L, Mitra R, Atkinson PW, Hickman AB, Dyda F, Craig NL. Transposition of hAT elements links transposable elements and $\mathrm{V}(\mathrm{D}) \mathrm{J}$ recombination. Nature. 2004;432:995-1001.

Zmasek CM, Eddy SR. ATV:display and manipulation of annotated phylogenetic trees. Bioinformatics. 2001;17:383-4.

Zou S, Kim JM, Voytas DF. The Saccharomyces retrotransposon Ty5 influences the organization of chromosome ends. Nucleic Acids Res. 1996;24:4825-31.

Zucchi MI, Arizono H, Morais VA, Fungaro MHP, Vieira MLC. Genetic instability of sugarcane plants derived from meristem cultures. Genet Mol Biol. 2002;25:91-6. 